\title{
Activation of $\beta$-Glucocerebrosidase Reduces Pathological $\alpha$-Synuclein and Restores Lysosomal Function in Parkinson's Patient Midbrain Neurons
}

\author{
Joseph R. Mazzulli, ${ }^{1,2}$ Friederike Zunke, ${ }^{2}$-Taiji Tsunemi, ${ }^{1,2}$ Nicholas J. Toker, ${ }^{2}$ Sohee Jeon, ${ }^{2}$ Lena F. Burbulla, ${ }^{1,2}$ \\ Samarjit Patnaik, ${ }^{3}$-Ellen Sidransky, ${ }^{4}$ Juan J. Marugan, ${ }^{3}$ Carolyn M. Sue, ${ }^{5}$ and Dimitri Krainc ${ }^{1,2}$ \\ ${ }^{1}$ Department of Neurology, Massachusetts General Hospital, Harvard Medical School, MassGeneral Institute for Neurodegeneration, Charlestown, \\ Massachusetts 02129, ${ }^{2}$ The Ken and Ruth Davee Department of Neurology, Northwestern University Feinberg School of Medicine, Chicago IL 60611, \\ ${ }^{3}$ Department of Preclinical Innovation, National Center for Advancing Translational Sciences, National Institutes of Health, Rockville, Maryland, 20850, \\ ${ }^{4}$ Section of Molecular Neurogenetics, Medical Genetics Branch, National Human Genome Research Institute, National Institutes of Health, Bethesda, \\ Maryland, 20892, and ${ }^{5}$ Department of Neurogenetics, Kolling Institute of Medical Research, Royal North Shore Hospital and the University of Sydney, St \\ Leonards, New South Wales 2065, Australia
}

Parkinson's disease (PD) is characterized by the accumulation of $\alpha$-synuclein ( $\alpha$-syn) within Lewy body inclusions in the nervous system. There are currently no disease-modifying therapies capable of reducing $\alpha$-syn inclusions in PD. Recent data has indicated that loss-offunction mutations in the GBA1 gene that encodes lysosomal $\beta$-glucocerebrosidase (GCase) represent an important risk factor for PD, and can lead to $\alpha$-syn accumulation. Here we use a small-molecule modulator of GCase to determine whether GCase activation within lysosomes can reduce $\alpha$-syn levels and ameliorate downstream toxicity. Using induced pluripotent stem cell (iPSC)-derived human midbrain dopamine (DA) neurons from synucleinopathy patients with different PD-linked mutations, we find that a non-inhibitory small molecule modulator of GCase specifically enhanced activity within lysosomal compartments. This resulted in reduction of GCase substrates and clearance of pathological $\alpha$-syn, regardless of the disease causing mutations. Importantly, the reduction of $\alpha$-syn was sufficient to reverse downstream cellular pathologies induced by $\alpha$-syn, including perturbations in hydrolase maturation and lysosomal dysfunction. These results indicate that enhancement of a single lysosomal hydrolase, GCase, can effectively reduce $\alpha$-syn and provide therapeutic benefit in human midbrain neurons. This suggests that GCase activators may prove beneficial as treatments for PD and related synucleinopathies.

Key words: $\alpha$-synuclein; glucocerebrosidase; induced pluripotent stem cells; lysosomes; Parkinson's disease; synucleinopathy

\section{Significance Statement}

The presence of Lewy body inclusions comprised of fibrillar $\alpha$-syn within affected regions of PD brain has been firmly documented, however no treatments exist that are capable of clearing Lewy bodies. Here, we used a mechanistic-based approach to examine the effect of GCase activation on $\alpha$-syn clearance in human midbrain DA models that naturally accumulate $\alpha$-syn through genetic mutations. Small molecule-mediated activation of GCase was effective at reducing $\alpha$-syn inclusions in neurons, as well as associated downstream toxicity, demonstrating a therapeutic effect. Our work provides an example of how human iPSC-derived midbrain models could be used for testing potential treatments for neurodegenerative disorders, and identifies GCase as a critical therapeutic convergence point for a wide range of synucleinopathies.

\section{Introduction}

Synucleinopathies are a class of age-dependent neurodegenerative disorders that include Parkinson's disease (PD), multiple system atrophy, and dementia with Lewy bodies (DLB; McCann

Received Feb. 25, 2016; revised May 15, 2016; accepted June 21, 2016.

Author contributions: J.R.M., F.Z., T.T., and D.K. designed research; J.R.M., F.Z., T.T., N.J.T., S.J., and L.F.B. performed research; S.P., E.S., J.J.M., and C.M.S. contributed unpublished reagents/analytic tools; J.R.M., F.Z., T.T., and D.K. analyzed data; J.R.M. and D.K. wrote the paper. et al., 2014). Although the clinical presentation and pathological distribution varies, all synucleinopathies are characterized by the accumulation of a normally soluble synaptic protein called $\alpha$-synuclein ( $\alpha$-syn) into insoluble amyloid fibrils that comprise 
Lewy body inclusions (Spillantini et al., 1997; Halliday et al., 2011). The most common synucleinopathy is PD, where the majority of cases are still considered sporadic. However, the recent emergence of genetic studies has identified important causative and risk genes that may lead to $\alpha$-syn accumulation and neurotoxicity including mutations in key mitophagy proteins, vesicular trafficking components, and autophagic/lysosomal pathways (van der Brug et al., 2015).

Loss-of-function mutations in the lysosomal GBA1 gene that cause Gaucher disease (GD) are one of the strongest risk factors for PD (Sidransky et al., 2009; Migdalska-Richards and Schapira, 2016). GBA1 encodes glucocerebrosidase (GCase) that functions to degrade glucosylceramide (GluCer) into glucose and ceramide in lysosomes (Brady et al., 1965). In human iPS neuronal cultures, mutation of GCase results in GluCer accumulation and subsequent stabilization of $\alpha$-syn within lysosomes (Mazzulli et al., 2011; Schöndorf et al., 2014). Previous work from our group and others has demonstrated that $\alpha$-syn can disrupt protein trafficking and/or lysosomal activity of wild-type (WT) GCase, and in turn, may result in GluCer accumulation in PD patient neuronal cultures (Mazzulli et al., 2011, 2016; Gegg et al., 2012; Chung et al., 2013; Yap et al., 2013). In addition, accumulation of GCase substrates have been observed in certain regions of synucleinopathy brain expressing WT GBA1 (Rocha et al., 2015a). Thus, neuronal accumulation of GCase substrates can occur in the context of both mutant and WT GCase expression, and substrate reduction may provide benefit in PD patients with and without GBA1 mutations.

In this study, we examined whether a previously identified noninhibitory small molecule modulator of GCase, NCGC00188758 (or 758; Patnaik et al., 2012), can activate GCase in synucleinopathy culture models. We find that 758 can enhance GCase activity specifically within the lysosomal compartment, reduce the GluCer and hexosylsphingosine substrates, and subsequently enhance the clearance of pathological $\alpha$-syn. We confirmed these findings in stable cell lines and multiple iPS neuronal lines derived from PD patients that harbor distinct mutations in SNCA (triplication or A53T), GBA1, or PARK9 genes, as well as idiopathic PD neurons, indicating the effectiveness of GCase activation in different genetic backgrounds. In addition, we find that 758 treatment could partially reverse $\alpha$-syn-induced cellular pathology, including perturbations in enzyme maturation, lysosomal hydrolase activity, and neurotoxicity. Our studies suggest that reduction of GluCer may provide benefit in PD, and strengthen the notion that GCase is a viable target for the treatment of synucleinopathies.

Department Biochemistry, Medical University of South Carolina (P20 RR017677); L.F.B. was supported by a fellowship within the postdoctoral program of the German Academic Exchange Service (DAAD); E.S. was supported by the Intramural Research Programs of the National Human Genome Research Institute; S.P. and J.J.M. by the Intramural Research Program of the National Center for Advancing Translational Sciences, both of the National Institutes of Health; C.M.S. by the NHMRC Practitioner Fellowship (1008433); National Institute of Neurological Disorders and Stroke Grants R01NS092823 (J.R.M.), R01NS076054, U24NS078338 (D.K.); and the PDNSW Association (C.M.S.). We thank Kana Hamada and Haris Dzaferbegovic for excellent technical assistance, Nick Blair and Ernst Wolvetang for advice and characterization of PARK9 PSC line, R. Jaenisch (MIT) for generously providing the A53T $\alpha$-syn iPSC lines, and Johannes Aerts (University of Leiden) for generously providing the anti-glucocerebrosidase antibody (8E4).

J.R.M. and D.K. are co-founders of Lysosomal Therapeutics, Inc, a company that uses lysosomal biology to develop treatments for neurodegenerative disease. None of the materials or reagents used in this work are propriety, and are therefore not directly related to the commercial interests of the company. The remaining authors declare no competing financial interests.

Correspondence should be addressed to either Dr Dimitri Krainc or Dr Joseph R. Mazzulli, The Ken and Ruth Davee Department of Neurology, Northwestern University Feinberg School of Medicine, 303 East Chicago Avenue, Ward 12-140, Chicago IL60611. E-mail: krainc@northwestern.edu or jmazzulli@northwestern.edu.

DOI:10.1523/JNEUROSCI.0628-16.2016

Copyright $\odot 2016$ the authors $\quad 0270-6474 / 16 / 367694-14 \$ 15.00 / 0$

\section{Materials and Methods}

\section{H4 cell culture}

Inducible human $\mathrm{H} 4$ cells expressing $\alpha$-syn under the control of a tetracycline inducible promoter (tet-off) have been described previously (Mazzulli et al., 2011). Cells were cultured in Optimem media containing $5 \%$ fetal bovine serum, $200 \mu \mathrm{g} / \mathrm{ml}$ geneticin and hygromycin, and $1 \%$ penicillin/streptomycin (from www.thermofisher.com). $\alpha$-Syn expression was turned off by the addition of $1 \mu \mathrm{g} / \mathrm{ml}$ doxycycline (DOX) for $2 \mathrm{~d}$. Cells were seeded into either 96 wells for live-cell activity assays at $3 \times 10^{4}$ per well or $1 \times 10^{5}$ per $35 \mathrm{~mm}$ size dish for Western blot. Either DMSO control or $10 \mu \mathrm{M} 758$ was added to the culture media for $3 \mathrm{~d}$, and replaced every day, followed by cell harvesting and assay measurements.

\section{iPS cell culture and differentiation into midbrain DA neurons}

These procedures have been described in detail previously (Mazzulli et al., 2016). Human induced pluripotent stem cells (iPSCs) were maintained in mTeSR1 media (http://www.stemcell.com/en/Products/AllProducts/mTeSR1.aspx) on vitronectin-coated dishes. All iPSC lines were reprogrammed from dermal fibroblasts of male [healthy control line 2135 or C3 from Mazzulli et al. (2016)], PARK9, A53T $\alpha$-syn, GD (GBA1 N370S/c.84dupG), idiopathic PD (Coriell line ND39896), or female (SNCA trp) by retroviral expression of OCT4, SOX2, cMYC, and KLF4 followed by clonal selection and pluripotency analysis. iPSCs were differentiated into midbrain dopamine (DA) neurons using an established protocol (Kriks et al., 2011). Neurons were maintained in Neurobasal media (ThermoFisher, 21103-049) containing NeuroCult SM1 supplement (Stemcell Technologies, 05711) and 1\% penicillin/streptomycin, until 758 treatment at $120 \mathrm{~d}$. Neurons were extensively characterized by immunostaining, RT-PCR, and Western blotting for midbrain markers FOXA2, LMX1a, and tyrosine hydroxylase (TH) at different time points in the differentiation protocol in our previous study, and all lines were found to differentiate at similar efficiencies (Mazzulli et al., 2016). The documentation of pathological $\alpha$-syn inclusions by immunocytochemical and biochemical techniques were previously published for lines SNCA trp, GD, and idiopathic PD (iPD), and demonstrated $\alpha$-syn inclusion formation starting at day 60 and persisting until day 330 (Mazzulli et al., 2016). The characterization of iPSCs and documentation of inclusions in A53T iPS neurons (lines WIBR-hiPS-SNCA ${ }^{\mathrm{A} 53 \mathrm{~T}}$, clone 2409 and WIBR-hiPS-SNCA ${ }^{\text {A53T-Corr }}$, clone 3849 ) has been previously demonstrated (Soldner et al., 2011; Ryan et al., 2013).

\section{Analysis of neurodegeneration}

iPS neurons were seeded on a PDL/laminin-coated 96-well plate and analyzed at day 200 . Treatment of 758 occurred $14 \mathrm{~d}$ before the assay. Cells were immediately fixed in $4 \%$ formaldehyde for $15 \mathrm{~min}$ and incubated with PBS containing 0.3\% Triton X-100 for 20 min, then blocked with Odyssey blocking buffer (LI-COR) for $1 \mathrm{~h}$. Anti-neurofilament antibody (1:1000; mouse IgG 2H3, Developmental Studies Hybridoma Bank) was then incubated overnight in blocking buffer at $4^{\circ} \mathrm{C}$, followed by washing in PBS with $0.1 \%$ Tween for $20 \mathrm{~min}$. IRdye 800 -conjugated anti-mouse IgG antibodies (1:1000 dilution, LI-COR) was then added in blocking buffer for $1 \mathrm{~h}$. CellTag 700 (LI-COR) was added with the secondary antibody for cell normalization. Cells were washed four times in PBS $0.1 \%$ Tween and scanned on an Odyssey infrared imaging system (LI-COR). Neurofilament intensity was determined using Odyssey software (v2.1, LI-COR) and normalized to cell volume. Toxicity assays were repeated four times and analyzed by Student's $t$ test using GraphPad Prism software v6.0.

\section{Characterization of PARK9 iPSC line}

Analysis of PARK9 iPSCs were performed essentially as described for other SNCA trp and GD iPSC lines (Mazzulli et al., 2011, 2016). iPSCs were analyzed for pluripotency by immunostaining for expression of pluripotency markers OCT4, Tra-1-60, SSEA4, Nanog, as well as ability to form mesoderm, endoderm, and ectoderm germ layers. Genomic integrity was documented by G-banding karyotype analysis. Analysis of PARK9 differentiated neurons was done by immunostaining for FOXA2 and $\mathrm{TH}$, and found to generate similar percentages of midbrain neurons compared with our previously characterized control lines (ctrl-1, 2, 3; 
Mazzulli et al., 2016). Expression of neuronal markers TH and synaptophysin was done by Western blot, and $\alpha$-syn accumulation was documented by sequential extraction in $1 \%$ Triton X-100 buffer (Tritonsoluble), and then $2 \%$ SDS with boiling (Triton-insoluble). Whole-cell GCase activity was measured in vitro as described below $(n=4)$.

\section{Treatment of cultures with GCase modulator 758}

Details on the specificity and effective target engagement of NCGC00188758 (758) have been published previously (Patnaik et al., 2012; Aflaki et al., 2014). Neurons were incubated with DMSO, 5 or 10 $\mu \mathrm{M} 758$ (containing equivalent volumes of DMSO for each condition) for $8-14 \mathrm{~d}$ as indicated, with media replacement every $2 \mathrm{~d}$. Five or $10 \mu \mathrm{M} 758$ was used to treat $\mathrm{H} 4$ cells for 3-5 d, with media change every day, followed by assays for GCase activity, Western blot, or immunofluorescence analysis. For calculations of live cell and lysosomal enzyme activity, with hydrolase-specific fluorescent substrates or general proteolysis, 758 was incubated with neurons for the same amount of time and was present in the culture wells during the assay. Live cell activity was calculated as described previously (Mazzulli et al., 2016).

\section{Western blot analysis}

Cells from a $35 \mathrm{~mm}$ dish (H4) or a 12-well-sized well (for iPS neurons) were harvested in PBS, pH 7.4, and cells were pelleted by centrifugation at $400 \times g$ for 5 min. Cell pellets were extracted in $1 \%$ Triton X-100 buffer (1\% Triton X-100, 20 mm HEPES, pH 7.4, 150 mm NaCl, 10\% glycerol, 1 mM EDTA, $1.5 \mathrm{~mm} \mathrm{MgCl} 2,1 \mathrm{~mm}$ phenylmethanesulfonyl fluoride, $50 \mathrm{~mm}$ $\mathrm{NaF}, 2 \mathrm{~mm} \mathrm{Na}$ orthovanadate, and a protease inhibitor cocktail (Roche Diagnostics, http://www.roche.com, 11-836-170-001) by homogenization, incubated on an ice-water slurry for $20 \mathrm{~min}$, frozen and thawed twice, and ultracentrifuged at $100,000 \times \mathrm{g}, 4^{\circ} \mathrm{C}$ for $30 \mathrm{~min}$. Tritonsoluble lysates ( $40 \mu \mathrm{g}$ per lane) were loaded onto 12\% SDS PAGE gels (for $\alpha$-syn) or 10\% gels (for GCase), transferred onto PVDF membranes (Millipore) and postfixed in $0.4 \%$ paraformaldehyde as described previously (Lee and Kamitani, 2011). Membranes were blocked in 5\% milk for $1 \mathrm{~h}$, and then incubated in primary antibodies overnight (LB509, Abcam, 1:100; syn211, ThermoFisher, 1:1000; C20, Santa Cruz Biotechnology, SC-7011-R, 1:2000; syn303, BioLegend, 1:1000). Antibodies against either GAPDH (Millipore) or $\alpha$-tubulin (Sigma-Aldrich) were used at 1:5000 after incubation with $\alpha$-syn antibodies. Antibodies against Hexosaminidase B (Santa Cruz Biotechnology, sc-376781) or GCase (SigmaAldrich, G4171) were used at 1:500. Monoclonal GCase anitbody 8E4 (gift from Johannes Aerts, University of Leiden, Leiden, The Netherlands), Synaptophysin (Millipore, MAB5258) and TH (Sigma-Aldrich, $\mathrm{TH}-2$ ) were used at 1:500. Detection was performed with fluorescentconjugated anti-rabbit or mouse antibodies with AlexaFluor 680 (ThermoFisher) or IRDye 800 (LI-COR), and scanned/quantified using a Odyssey infrared imaging system (LI-COR Biosciences).

\section{In vitro activity assay of GCase}

Neurons were washed in PBS, harvested in $1 \%$ Triton lysis buffer, and activity was measured from whole-cell lysates as described previously (Mazzulli et al., 2011) using 4-methylumbelliferyl $\beta$-D-glucopyranoside (4MU-Gluc; Sigma-Aldrich). To determine whether 758 directly activates GCase in lysates, 758 was added at a final concentration of $10 \mu \mathrm{M}$ into the activity assay buffer at the same time as the $4 \mathrm{MU}-$ Gluc substrate. Lysates [ $\pm 1 \mu \mathrm{M}$ conduritol-b-epoxide (CBE)] were incubated for $30 \mathrm{~min}$, and the assay was stopped by addition of equi-volume $1 \mathrm{~m}$ glycine, $\mathrm{pH}$ 12.5. 4MU fluorescence was detected in white fluoro plates (Nunc, 136101) and fluorescence (ex $=355 \mathrm{~nm}$, $\mathrm{em}=460)$ was determined in a Molecular Devices i3 microplate reader. Relative fluorescent units (RFUs) from CBE-treated lysates were subtracted from non-CBE-treated lysates to obtain activity derived from GBA1, and RFUs were expressed as fold-change compared with DMSO control. The residual activity in CBE-treated samples was graphed as percentage of non-CBE-treated samples.

\section{Lysosomal live-cell activity assay}

These procedures have been described in detail previously (Mazzulli et al., 2016), using 5-(pentafluorobenzoylamino) fluorescein Di- $\beta$-Dglucopyranoside (PFB-FDGlu; ThermoFisher, ) as the substrate. The degradation of PFB-FDGlu was followed for $3 \mathrm{~h}$ by measuring fluorescein fluorescence in a Molecular Devices SpectraMax i3 microplate reader. Values were normalized to cell volume using CellTag 700. Activity within the lysosomal compartment was determined by measuring the response to bafilomycin A1 (baf A1). Non-lysosomal GCase activity was interpreted as the activity that was not responsive to baf A1 (Fig. 1C). The area under each curve (AUC) was quantified with GraphPad Prism software v6.0 g, and AUC from baf Al was subtracted from DMSO to obtain lysosomal activity.

\section{Pathological analysis of $\alpha$-synuclein by}

immunofluorescence staining

Neurons were fixed in $4 \%$ paraformaldehyde for $15 \mathrm{~min}$, permeabilized with $0.1 \%$ Triton X-100 in PBS, then blocked in 2\% BSA, $5 \%$ normal goat serum in PBS-Triton for $30 \mathrm{~min}$. LB509 (1:100) and anti-TH antibodies (1:100; Merck Millipore, 657012) were incubated overnight, washed in PBS-Triton, then AlexaFluor 568-conjugated anti-mouse IgG was used to detect $\alpha$-syn,whereas AlexaFluor 488-conjugated anti-rabbit was used to detect TH. Next, thioflavin S (Thio S) staining was performed as previously described (Mazzulli et al., 2006). The number of cells with $\alpha$-syn and Thio $S$ in the cell body [as either a diffuse (type I) or punctated (type II) pattern, as characterized in our previous study; Mazzulli et al., 2016] were scored and normalized to total cells in the field-of-view (calculated by nuclear DAPI stain). Only the Thio $\mathrm{S}+$ cells that colocalized with $\alpha$-syn were counted. Neuritic pathology was calculated by counting the number of $\alpha$-syn + neurites that colocalized with Thio S, and divided by the total number of neurites in the field-of-view. At least three fields of view were used per coverslip, and 100-500 cells counted per condition, per cell line. Images were obtained on a Leica epifluorescence microscope using a $40 \times$ objective (DMI3000B). To determine synaptic localization of $\alpha$-syn, neurons were fixed as described but permeabilized in $0.1 \%$ Triton-containing blocking buffer. Anti-synapsin antibodies (ThermoFisher, A6442; 1:50 dilution) with LB509 (1:100 dilution) were detected with AlexaFluor-conjugated secondary antibodies and analyze by confocal microscopy as described previously (Mazzulli et al., 2016). Synapsin/ $\alpha$-syn colocalized puncta were quantified from merged images and expressed as fold-change compared with control conditions. The quantification represents the mean ( \pm SEM) from five different fields-of-view from different culture wells with 100-200 puncta counted per field.

Analysis of GCase subcellular localization by immunofluorescence. $\mathrm{H} 4$ cells were seeded on cover glass at a cell number of $4 \times 10^{4} / 24$ wells. Cells were treated with DOX $(2 \mu \mathrm{g} / \mathrm{ml})$ for $5 \mathrm{~d}$ to turn off $\alpha$-syn expression. For 758 analysis, $\mathrm{H} 4$ cells were cultured without DOX and treated with compound $758(5 \mu \mathrm{M})$ or DMSO for $5 \mathrm{~d}$. Cells were fixed in $4 \%$ PBS-buffered paraformaldehyde for $20 \mathrm{~min}$ and washed three times in PBS. Cells were permeabilized with $0.2 \%$ saponin (w/v)/PBS for $5 \mathrm{~min}$, then with $0.2 \%$ (w/v) glycine/0.2\% saponin in PBS, and blocked with $2 \%$ bovine serum albumin, $5 \%$ normal goat serum (Jackson Immunofluorescence) in $0.2 \%$ saponin/PBS for $30 \mathrm{~min}$. Primary antibodies [anti-GCase, gift from Johannes Aerts, University of Leiden, NL; anti-LAMP2, Invitrogen, 512210; anti-protein disulfide isomerase (PDI) Abcam, ab11432] were diluted 1:100 in blocking buffer, incubated overnight at $4^{\circ} \mathrm{C}$, then washed and incubated with secondary antibodies (AlexaFluor 568-conjugated anti-mouse, and AlexaFluor 488-conjugated anti-rabbit, 1:400 dilution). Cells were mounted on microscope slides using DAPI-Fluoromount G (Southern Biotech) and imaged using a Leica confocal microscope as described previously (Mazzulli et al., 2016). Images were analyzed by ImageJ software using the colocalization plugin Coloc 2. Pearson correlation values of GCase + LAMP2, or GCase + PDI were obtained from six fields-of-view from different culture wells for each condition, and data were expressed as fold-change compared with the control condition. The quantifications represent the mean \pm SEM.

\section{Quantification of GluCer and hexosylsphingosine}

DMSO or 758-treated SNCA trp neurons from two lines were treated with $10 \mu \mathrm{M} 758$ for $14 \mathrm{~d}$, starting at day 200 . Neurons from a $35 \mathrm{~mm}$ sized dish were harvested in PBS and cell pellets were homogenized $0.25 \mathrm{M}$ sucrose buffer containing $10 \mathrm{~mm}$ HEPES, pH 7.4, and $10 \mathrm{~mm}$ EDTA followed by subcellular fractionation to obtain a lysosome-enriched pel- 
A

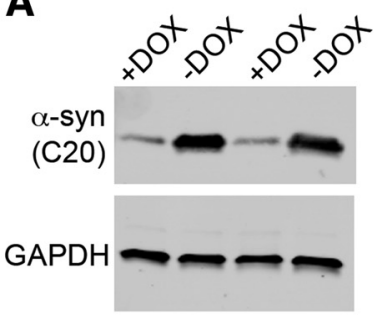

C

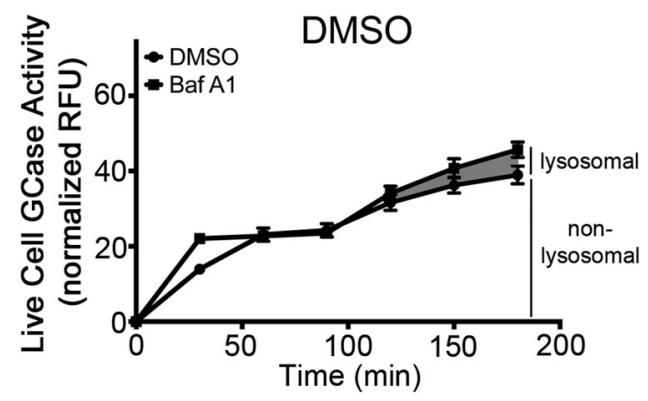

B

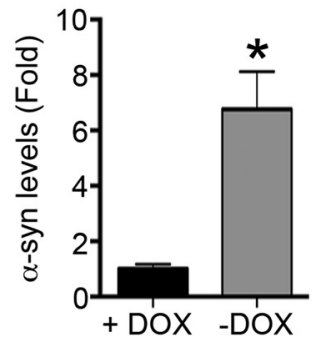

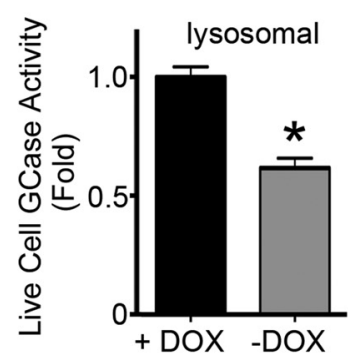
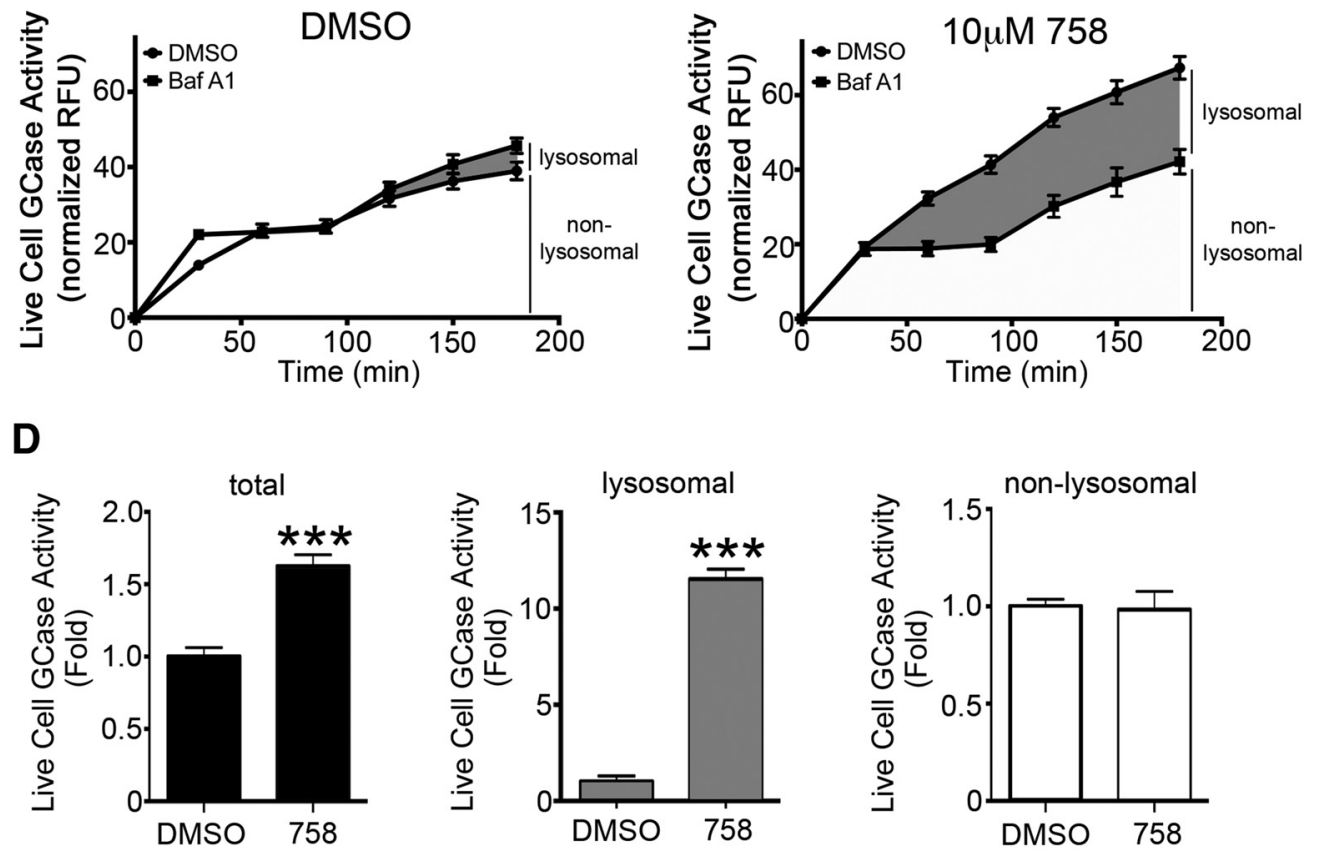

D

E

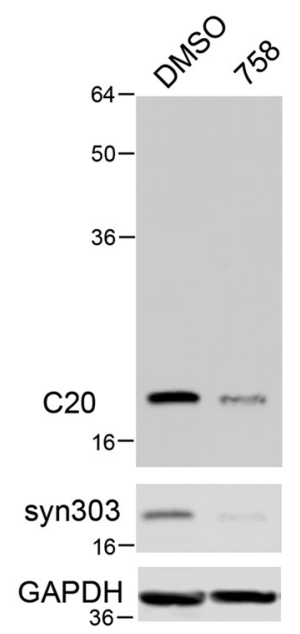

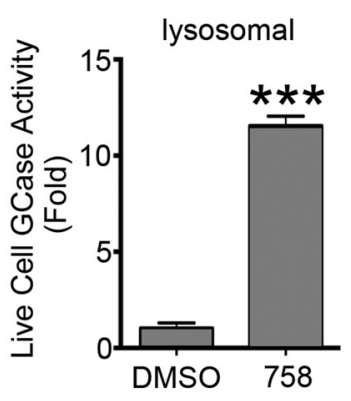

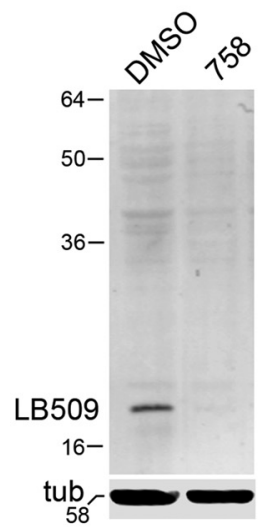

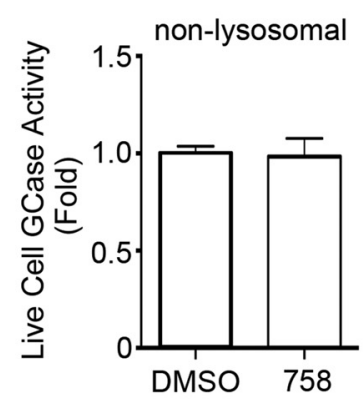

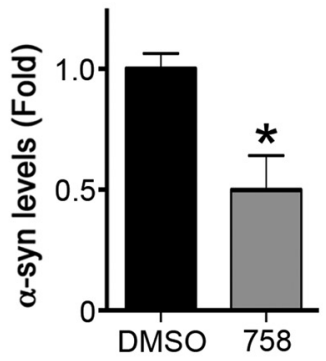

Figure 1. Small molecule modulator 758 enhances $\mathrm{GCase}$ activity within lysosomal compartments and reduces $\alpha$-syn. Inducible $\mathrm{H} 4$ cells that express $\alpha$-syn under the control of a tetracycline-responsive promoter (tet-off) were treated with $10 \mu \mathrm{m} 758$ and harvested 3 d later. $A$, Lysates from H4 $\alpha$-syn cells treated with D0X for 48 h to turn off $\alpha$-syn expression were analyzed by Western blot. GAPDH was used as a loading control. Right, Quantification of $\alpha$-syn levels with the C20 antibody normalized to GAPDH. Values are expressed as fold-change compared with +DOX $(n=3)$. B , Lysosomal GCase activity was measured in living H4 cells treated with D0X for $48 \mathrm{~h}$ by quantifying the degradation of PFB-FDGlu over $3 \mathrm{~h}$. Activity within lysosomal compartments was achieved by measuring the response to baf $\mathrm{A} 1(n=4)$. C, Treatment of $10 \mu \mathrm{m} 758$ for $3 \mathrm{~d}$ elevates the lysosomal GCase activity but does not alter non-lysosomal activity. GCase activity in $\mathrm{H} 4$ cells was quantified by measuring fluorescence upon the cleavage of PFB-FD-Glu substrate over time. RFU, relative fluorescent units. Parallel cultures were treated with baf A1 to obtain lysosome and non-lysosomal activity. D, Quantification and statistical analysis of total, lysosomal, and non-lysosomal activities from the kinetic data obtained in C. E, Triton-soluble lysates from 758-treated H4 cells were analyzed by Western blot for $\alpha$-syn using either C20, syn303, or LB509 antibodies. Molecular weight marker is indicated in kilodaltons. Right, Quantification of $\alpha$-syn using $\left(20\right.$ normalized to GAPDH $(n=3)$. For all quantifications, values are the mean \pm SEM. ${ }^{*} p<0.05,{ }^{* * *} p<0.001$. 
A

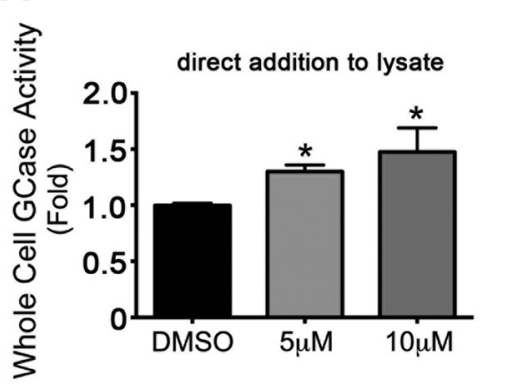

C

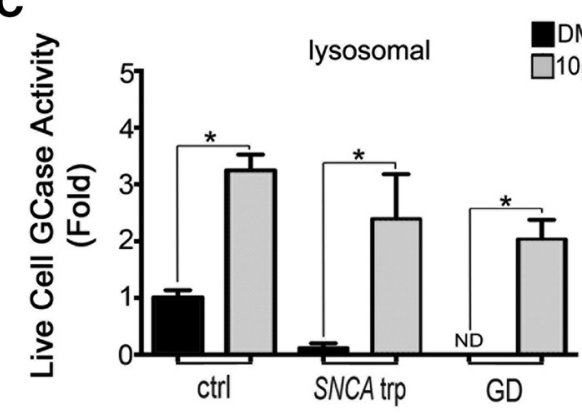

B
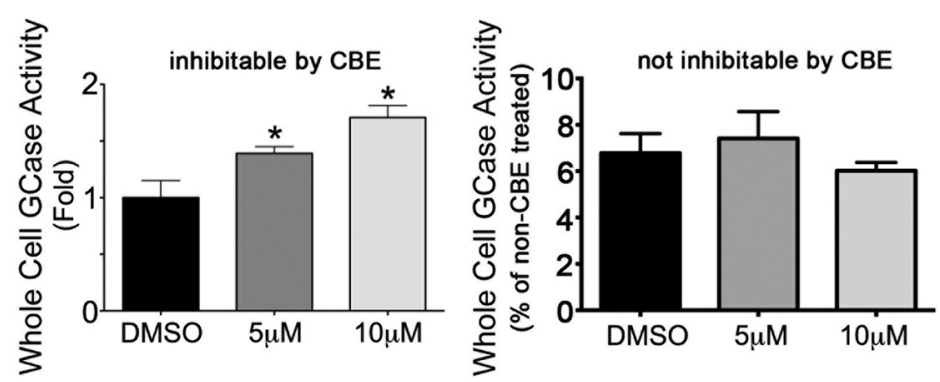

DMSO $10 \mu \mathrm{M} 758$

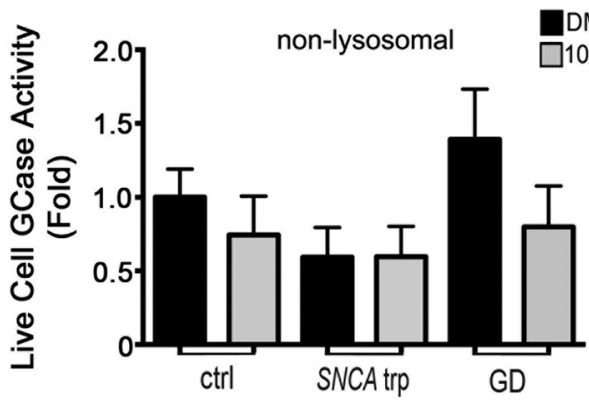

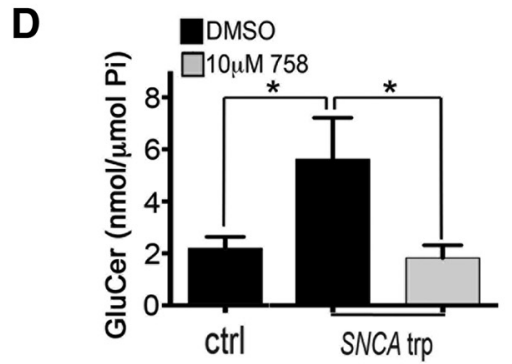

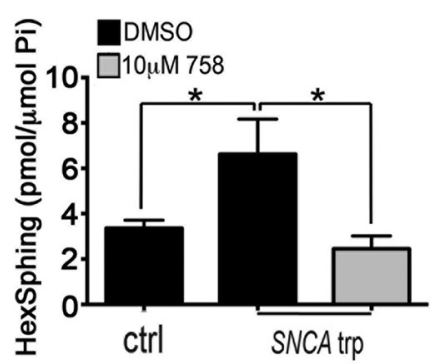

Figure 2. 758 directly enhances GCase activity within lysosomes and reduces lipid substrates in human midbrain synucleinopathy models. A, 758 was added to whole-cell lysates extracted from day 90 SNCA trp neurons and activity was measured by the cleavage of 4-MU-Gluc $(n=3) . B, S N C A$ trp neurons were incubated for $8 \mathrm{~d}$ with 758, washed, and whole-cell lysates were used for activity analysis with 4-MU-Gluc $(n=4)$. CBE was added in parallel samples to distinguish between GBA7 (lysosomal) and GBA2 (cytosolic)-derived hydrolysis of 4-MU-Gluc. C, Lysosomal GCase activity was measured in living neurons at day 120 using PFB-FD-Glu through quantifying the response to baf A1 (AUC obtained from a kinetic activity assay; $n=4$ ). D, Measurement of GluCer from lysosome-enriched fractions or hexosylsphingosine (HexSphing) from whole-cell lysates obtained from control and SNCA trp d 200 neurons treated for $14 \mathrm{~d}$ with DMSO or 758 . Values were normalized to inorganic phosphate $(\mathrm{Pi} ; n=4)$. For all quantifications, values are the mean $\pm \mathrm{SEM} .{ }^{*} p<0.05$.

let as described previously (Mazzulli et al., 2011). Lipids from lysosomalenriched pellets were extracted and quantified as a service provided by the lipidomics core facility at the Medical University of South Carolina as described previously (Mazzulli et al., 2016).

\section{Live-cell proteolysis assay}

SNCA trp neurons at day 180 were treated with $10 \mu \mathrm{M} 758$ for $14 \mathrm{~d}$ and then proteins were trace-labeled by incubation of tritium-labeled leucine for $48 \mathrm{~h}$. Cultures were washed three times, chased with media containing cold leucine, and media samples were collected at 0,12 , and $24 \mathrm{~h}$ postchase. Proteolysis rates were obtained by quantifying acid-soluble tritium (representing free amino acids and small peptides) in the media with a PerkinElmer Scintillation counter. The data were analyzed as described previously (Mazzulli et al., 2011).

\section{Analysis of lysosomal hydrolase maturation and carbohydrate moieties}

H4 neuroglioma cells were cultured as described above and $20 \mu \mathrm{g}$ of lysate was treated with endoglycosidase $\mathrm{H}$ (Endo $\mathrm{H}$ ) or peptide $\mathrm{N}$-glycosidase F (PNGase F; New England Biolabs) according to the manufacturer's instructions. Digested lysates were loaded onto 10\% SDSPAGE gels and analyzed by Western blot using anti-GCase (8E4) or nicastrin (Cell Signaling Technologies, 3632S; 1: 500 dilution). Post-ER bands (migrating $>64 \mathrm{kDa}$ ) of lysates with and without Endo $\mathrm{H}$ treat- ment were quantified and normalized to GAPDH using an Odyssey infrared imager and Image Studio software (LI-COR). Post-ER levels from non-Endo $\mathrm{H}$-treated lysates were divided by the post-ER quantity obtained from Endo H-treated lysates and data were expressed as foldchange compared with -DOX or DMSO. The assay was repeated four times from lysate obtained from different culture wells and values represent the mean \pm SEM.

For maturation analysis in human iPS neurons, SNCA trp or GD neuronal lysates were analyzed by Western blot for hexosaminidase $B$ or GCase. Mature and immature forms of each hydrolase were identified by well established weight changes that occur during the maturation process through proteolytic processing and stage-specific glycosylation (Bolhuis et al., 1987; Bergmann and Grabowski, 1989). Mature and immature forms of GCase and hexosaminidase B (Hex B) were quantified and maturation value was expressed as mature: immature ratios. To determine whether elevated mature forms of hydrolases were active in the lysosome, the live-cell compartmentspecific activity assay was performed to quantify hydrolase activity within acidic organelles.

\section{Statistical analysis}

Statistical tests were performed using GraphPad Prism software v6 (http://www.graphpad.com/scientific-software/prism/). ANOVA with 
A
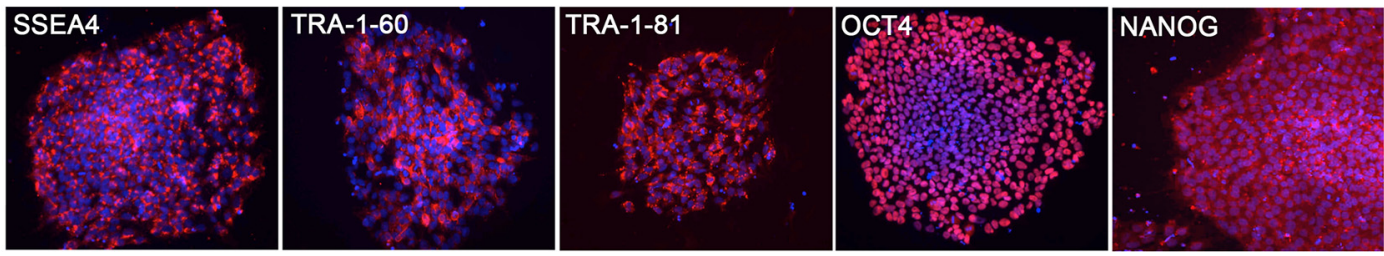

B

C
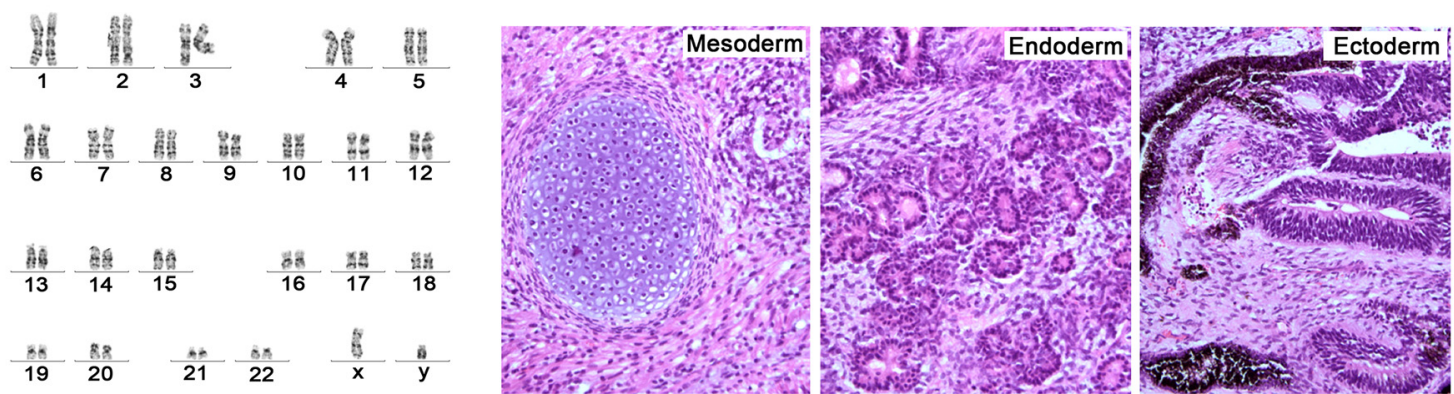

D
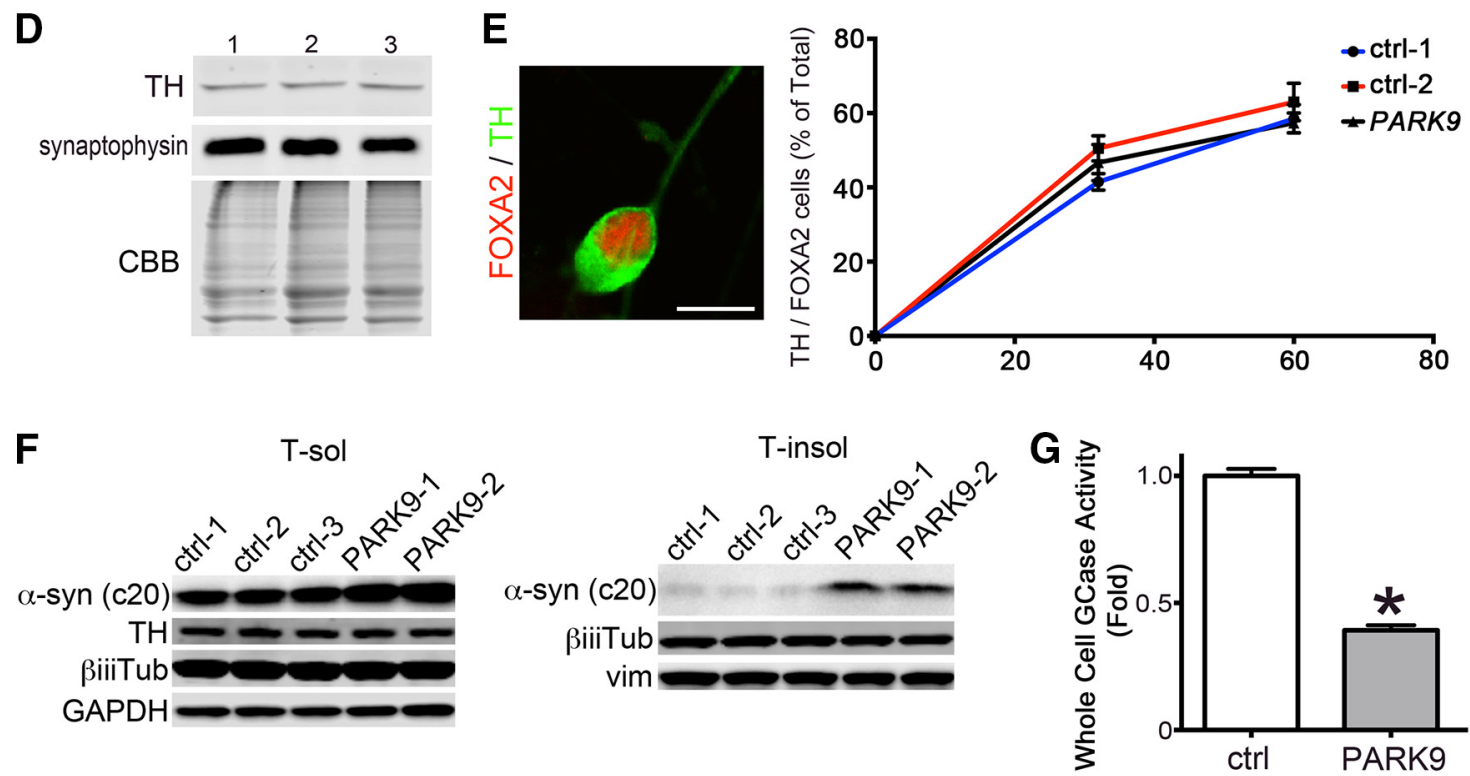

Figure 3. Characterization of PARK9iPSC and differentiation into midbrain DA neurons. Fibroblasts from a patient harboring PARK9 mutations (L1059R/c.3176T >C; L1085WfSX1088/C.3253delC) were reprogrammed into iPSCs by retroviral expression of OCT4, SOX2, CMYC, and KLF4. A, Immunofluorescence analysis of pluripotency markers of PARK9iPSCS. $B$, G-banding karyotype analysis of PARK9 iPSCs demonstrates normal male genomic phenotype. $C$, Hematoxylin and eosin-stained sections of teratomas demonstrate pluripotency of PARK9 iPSCs through differentiation into mesoderm-, endoderm-, and ectoderm-derived structures. D, Western blot analysis of PARK9 PSS differentiated into midbrain DA neurons at day 90 shows expression of TH and synaptophysin. Coomassie brilliant blue (CBB) is shown as a loading control $(n=3$ ). Analysis of 3 different samples is shown. $\boldsymbol{E}$, Immunostaining analysis of F0XA2 (red) and TH (green) of PARK9 midbrain neurons at day 60. Scale bar, $10 \mu \mathrm{m}$. Right, Quantification of neurons expressing both TH and FOXA2, compared with previously established lines from healthy controls (Mazzulli et al., 2016). $\boldsymbol{F}$, Sequential extraction/Western blot analysis of $\alpha$-syn using antibody (20. Day 90 neuronal lysates from three different healthy controls or two PARK9 clones were separated into Triton-soluble (T-sol) and -insoluble (T-insol) fractions. Loading controls include neural-specific $\beta$-iii-Tubulin, GAPDH, or vimentin (vim). G, GCase activity from whole-cell extracts using 4-MU-Gluc, obtained from PARK9 neurons at day $90(n=4)$. For all quantifications, values are the mean \pm SEM. ${ }^{*} p<0.05$.

Tukey's post hoc test was used in Figures $2 A, B, D, 4 A, B, 6 B, 8 A, B$, whereas Student's $t$ test (two-sided) was used in all other analyses.

\section{Results}

Previous studies identified a non-inhibitory small molecule, 758, capable of modulating GCase activity in vitro and in GD macrophages (Patnaik et al., 2012; Aflaki et al., 2014). To determine whether 758 can modulate GCase activity in synucleinopathy models, we first used an established inducible $\mathrm{H} 4$ neuroglioma model of $\alpha$-syn overexpression (tet-off; Mazzulli et al., 2011, 2016). Measurement by quantitative Western blot indicated that
H4 cells overexpressed $\alpha$-syn by nearly sevenfold compared with parallel cultures where $\alpha$-syn expression was turned off by addition of doxycycline to the culture media (Fig. 1A). To determine whether $\alpha$-syn accumulation reduces lysosomal GCase activity in $\mathrm{H} 4$ cells, we used a compartment-specific assay capable of measuring activity within acidic subcellular compartments through quantifying the response to baf A1 (Mazzulli et al., 2016). We found that $\alpha$-syn accumulation reduced GCase activity within acidic compartments (Fig. 1B). Treatment with $10 \mu \mathrm{M} 758$ for $3 \mathrm{~d}$ significantly elevated lysosomal GCase activity, but did not change the activity of 
A

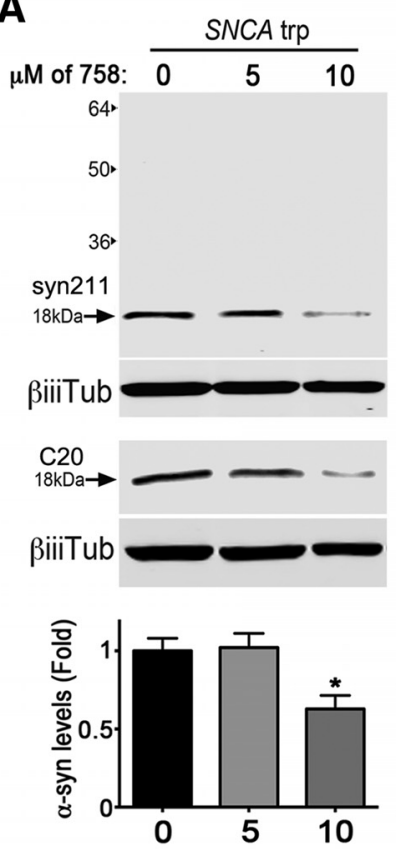

B
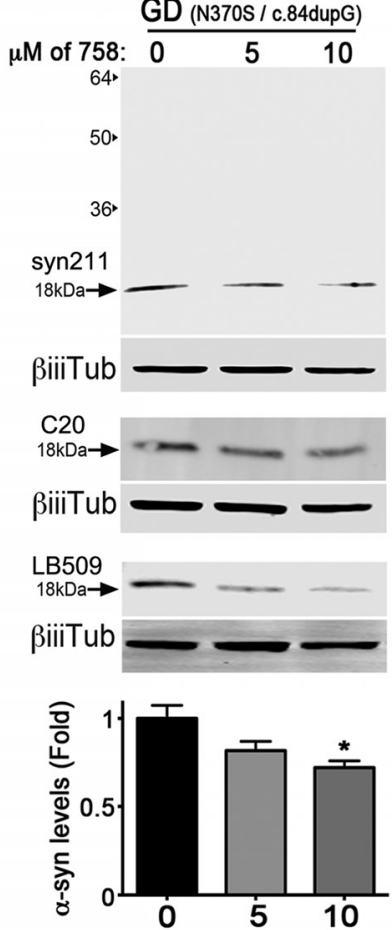

C

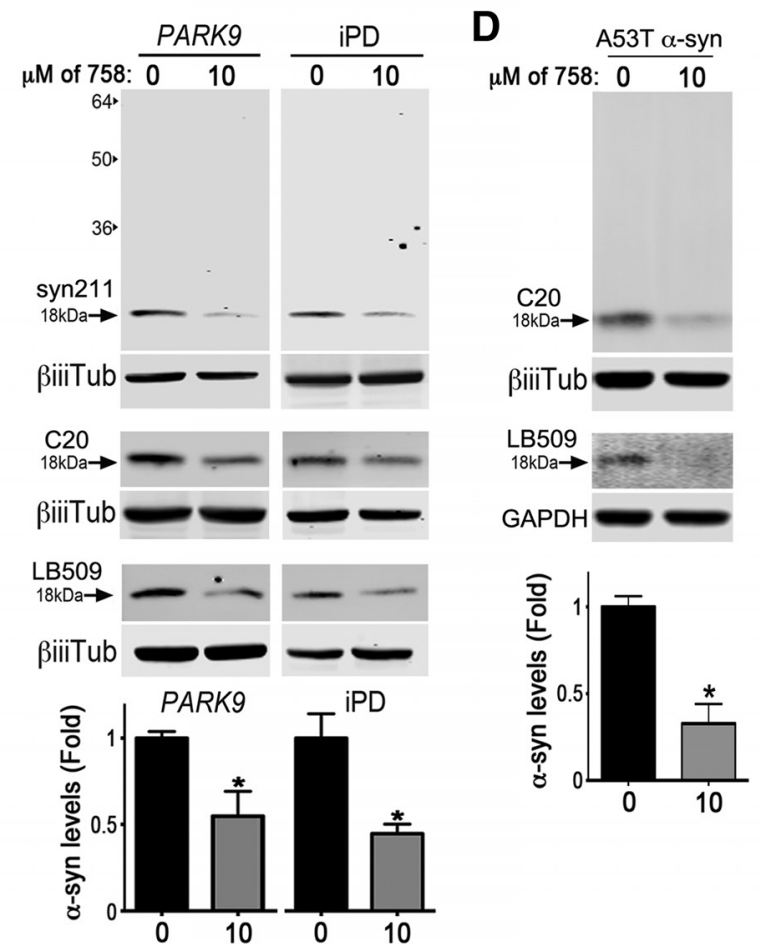

Figure 4. Reduction of $\alpha$-syn by 758 in human midbrain synucleinopathy models. SNCA trp (A) or GD (N370S/ c.84dupG; B) patientneurons at day 120 were incubated with 0,5, or $10 \mu \mathrm{m} 758$ for 8 d, extracted in $1 \%$ Triton X-100 buffer, and analyzed by Western blotfor $\alpha$-syn (antibodies syn211, (20, or LB509). Bottom, Quantification of $\alpha$-syn normalized to loading control $\beta$-iii-tubulin using syn211 ( $n=4)$. C, Western blot analysis and quantification of $\alpha$-syn from day 90 neuronal lysates of PARK9 or iPD patients $(n=4)$. $\boldsymbol{D}$, Western blotand quantification of $\alpha$-synfrom A53T $\alpha$-synmidbrainneurons $(n=3)$. For all quantifications, values are the mean \pm SEM. ${ }^{*} p<0.05$. Molecular weight marker is indicated in kilodaltons.

non-lysosomal GCase (Fig. 1C,D). Quantification of $\alpha$-syn levels by Western blot using antibody C20 that detects total $\alpha$-syn indicated that 758 significantly reduced $\alpha$-syn (Fig. $1 E$ ). We confirmed this finding with two additional antibodies that preferentially detect ox- idized/nitrated $\alpha$-syn (syn303; Duda et al., 2002), or aggregated $\alpha$-syn generated against Lewy body inclusions (Baba et al., 1998; Fig. $1 E)$. This indicates that 758 is capable of elevating GCase activity specifically within lysosomes and can reduce pathological $\alpha$-syn in H4 neuroglioma cells.

We next sought to confirm our findings in midbrain DA neurons derived from PD patients. Neurons were generated from previously established and extensively characterized iPSC lines that harbor mutations in the GBA1 gene (N370S/c.84dupG) or a triplication in the SNCA gene (SNCA trp; Mazzulli et al., 2011, 2016). We previously found that all iPS lines differentiated into DA neurons similarly, and accumulated pathological $\alpha$-syn inclusions (Mazzulli et al., 2016). To confirm that 758 could directly activate GCase extracted from SNCA trp neurons, lysates were incubated with 758 during an in vitro activity assay using the artificial fluorescent GCase substrate, 4-MU-Gluc. This revealed a dose-dependent elevation in total GCase enzymatic activity, with a $\sim 1.5$-fold increase observed at $10 \mu \mathrm{M}$ (Fig. $2 A$ ). Next, we incubated living neuronal cultures with 758 by addition to the culture media for $8 \mathrm{~d}$, washed the cultures, and then measured total activity in whole-cell extracts. To determine whether 758 selectively activated lysosomal GBA1 but not the related cytosolic enzyme encoded by $G B A 2$, the activity assay was performed in the presence or absence of CBE that selectively inhibits GBA1 but not GBA2 (van Weely et al., 1993). This showed an elevation only in the activity that was inhibitable by CBE, indicating that 758 specifically enhanced activity of $G B A 1$ and not $G B A 2$ within neurons (Fig. $2 B$ ). Finally, to exclude the possibility that 758 activated GCase after cell lysis, we measure activity in living neurons. This confirmed that 758 could enhance GCase activity within lysosomal compartments in patient neurons that express either WT or N370S mutant GCase with no affect on non-lysosomal activity (Fig. 2C).

Because we previously found that GluCer accumulated in SNCA trp neurons expressing WT GBA1 (Mazzulli et al., 2016), we next determined the effect of 758 on GCase substrate levels by measuring both GluCer and hexosylsphingosine. Importantly, the level of GCase activity achieved by 758 was sufficient to reduce GluCer levels when measured from lysosome-enriched subcellular fractions, as well as hexosylsphingosine levels from whole-cell extracts of SNCA trp neurons (Fig. 2D). This demonstrates that 758 can activate GCase in patient neurons sufficiently to reduce lipid substrates.

Because several groups have found that reduced GCase activity can lead to $\alpha$-syn accumulation in neurons (Manning-Boğ et al., 2009; Mazzulli et al., 2011, 2016; Xu et al., 2011; Cleeter et al., 2013; Schöndorf et al., 2014; Bae et al., 2015; Rocha et al., 2015c), we next determined whether enhancement of GCase activity by 758 could reduce $\alpha$-syn accumulation in patient midbrain neurons. In addition to our already established iPSC lines [SNCA trp, GBA1 (N370S/c.84dupG), and iPD; Mazzulli et al., 2016], we generated an additional PD patient line that harbors mutations in PARK9(L1059R/c.3176T > C; L1085WfsX1088/c.3253delC; Park et al., 2011). Characterization of PARK9 iPSC's showed the expression of pluripotency markers, normal genomic structure, and capability of forming all three germ layers (Fig. $3 A-C$ ). Differentiation of PARK9 iPSC's into midbrain neurons showed expression of TH by Western blot and immunofluorescence analysis at similar efficiency compared with other established control iPSC lines (Fig. $3 D, E$ ). Consistent with previous data indicating that PARK9 mutations lead to $\alpha$-syn accumulation (Gitler et al., 2009; Schultheis et al., 2013; Tsunemi and Krainc, 2014), Western blot analysis showed the accumulation of soluble and insoluble 
A
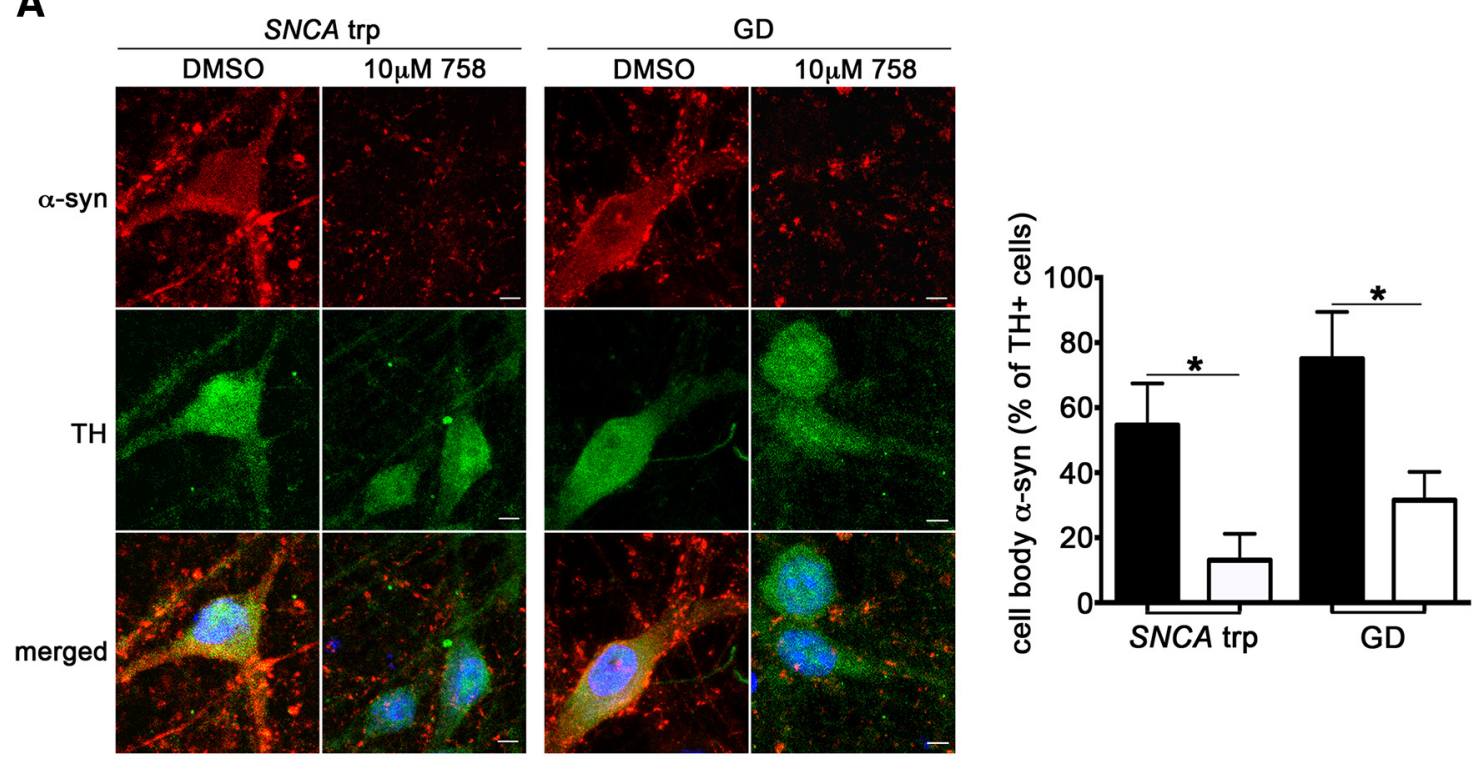

B
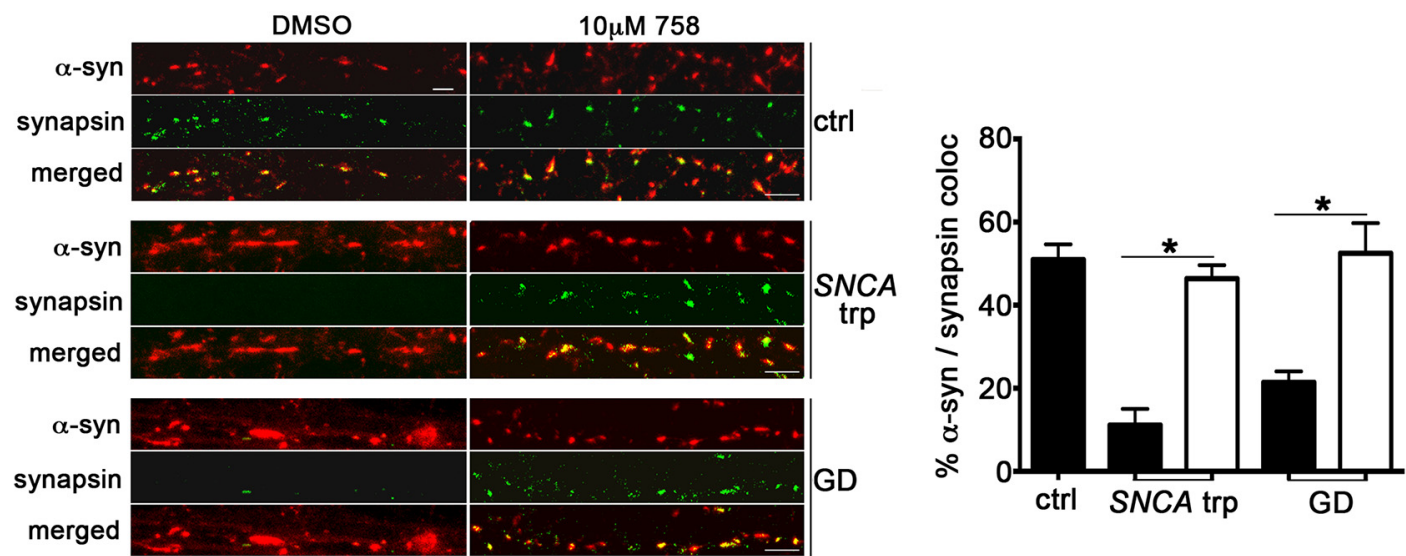

Figure 5. Reduction of cell body accumulation of $\alpha$-syn and restoration of synaptic localization by 758 . Human midbrain neurons from SNCA trp and GD patients at day 120 were treated with 758 for $8 \mathrm{~d}$, fixed, and analyzed by immunofluorescence. $A$, Cell body accumulation of $\alpha$-syn detected with LB509 (red) and dopaminergic neurons were detected by TH staining (green). Nuclei were detected with DAPI (blue). Scale bar, $5 \mu \mathrm{m}$. Right, Quantification of TH-positive cells that contained $\alpha$-syn in the cell body $(n=6)$. B, Analysis of synaptic $\alpha$-syn (LB509, red) in neurites by colocalization with a synaptic marker, synapsin (green). Scale bar, $5 \mu \mathrm{m}$. Right, Quantification of $\alpha$-syn puncta that colocalized with synapsin (percentage of total puncta calculated per field-of-view, $n=6$ ). For each quantification, values are the mean \pm SEM. ${ }^{*} p<0.05$.

$\alpha$-syn within extracts of PARK9 midbrain neurons (Fig. 3F), as well as a $60 \%$ reduction in whole-cell GCase activity (Fig. $3 G$ ).

To determine the effect of GCase activation on $\alpha$-syn in patient lines, cultures were incubated for $8 \mathrm{~d}$ with 758 and neuronal extracts were analyzed by Western blot. This treatment resulted in a reduction of $\alpha$-syn levels in both SNCA trp and GD neurons, a finding that was confirmed with multiple $\alpha$-syn antibodies (syn211, C20, and LB509; Fig. 4A,B). We next treated midbrain neurons derived from a previously characterized iPD patient line (Coriell, ND39896) and PARK9 neurons to determine whether 758 could reduce $\alpha$-syn in neurons from a broader range of synucleinopathies. We found that 758 also significantly reduced $\alpha$-syn levels in these neuronal lines (Fig. 4C). Finally, we found similar effects in neurons derived from a familial PD patient that harbors the A53T $\alpha$-syn mutation (Fig. 4D; Soldner et al., 2011). This indicates that GCase activation can reduce $\alpha$-syn in human midbrain neurons derived from multiple synucleinopathy cases, regardless of the mutation that initiates $\alpha$-syn accumulation.

Our previous analysis of midbrain neurons generated from iPSCs indicated that $\alpha$-syn is predominantly located at synapses in healthy controls, whereas it aberrantly accumulates in the cell body PD patient neurons over time (Mazzulli et al., 2016). To determine whether 758 could reduce cell body accumulation of $\alpha$-syn within dopaminergic neurons, we analyzed 758 -treated SNCA trp and GD cultures by immunofluorescence. This revealed a decline in $\alpha$-syn staining intensity within cell bodies of neurons that express $\mathrm{TH}$, a marker for dopaminergic neurons (Fig. 5A). Immunostaining analysis also showed improved synaptic-localized $\alpha$-syn by increased colocalization with the synaptic marker synapsin (Fig. 5B), indicating that 758 could partially restore $\alpha$-syn to its proper location within midbrain neurons. Next, we tested the ability of 758 to reduce pathological, amyloidogenic $\alpha$-syn in SNCA trp and GBA1 mutant patient neurons by Thio $S$ staining, a dye that specifically intercalates and fluoresces upon binding to amyloid-rich structures. Consistent with Western blot analysis and reduction of $\alpha$-syn within TH+ cell bodies, we found that 758 treatment reduced the amyloidogenic $\alpha$-syn accumulation that occurred at the cell body as a diffuse accumulation (type I), as well as punctated juxtanuclear inclusions (type II; Fig. 6A). Neuritic pathology was also dramat- 
A
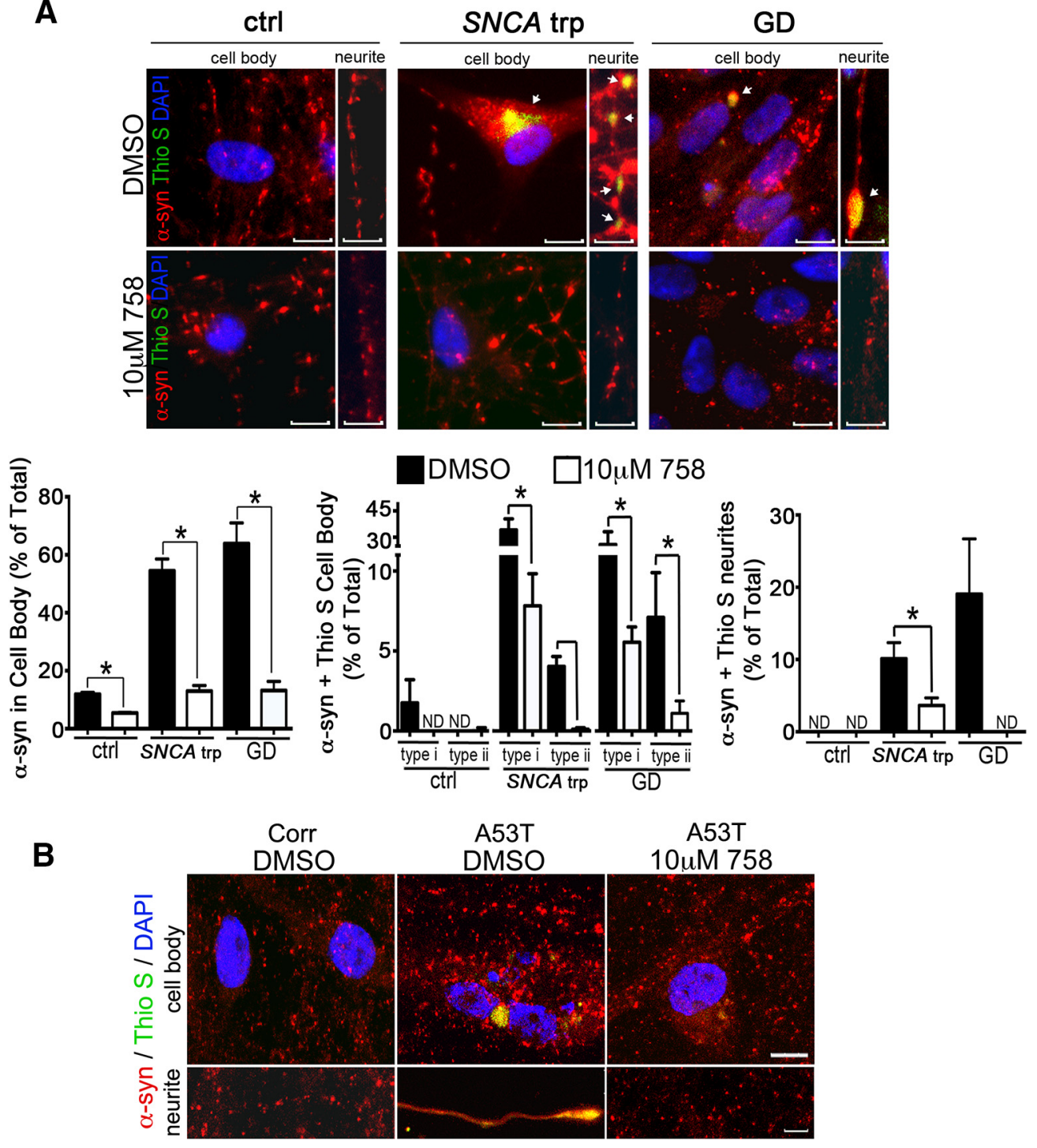

A53T

B

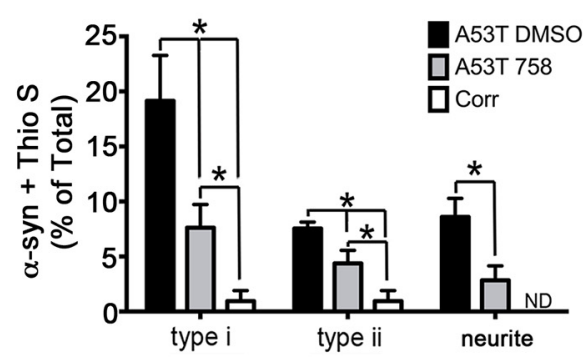

Figure 6. Reduction of pathological $\alpha$-syn aggregates in human synucleinopathy midbrain models by 758 . A, Immunofluorescence analysis of $\alpha$-syn using antibody LB509 (red) in SNCA trp and GD neurons treated with $10 \mu \mathrm{m} 758$ for $8 \mathrm{~d}$. Amyloidogenic structures were detected with Thio S (green), and nuclei (DAPI) are shown in blue. 758 (10 $\mu \mathrm{m}$ ) reduced Thio $\mathrm{S}$ staining and restored the normal punctated pattern of $\alpha$-syn in SNCA trp and GD neurons at day 120. Scale bar, $10 \mu \mathrm{m}$. Bottom, Quantification of cells and neurites containing $\alpha$-syn/Thio Saccumulations $\left(n=4,{ }^{*} p<0.05\right)$. Both type I (diffuse cytoplasmic inclusions) and type II (punctated juxtanuclear) inclusions were quantified. $\boldsymbol{B}$, Pathological analysis of $\alpha$-syn was done as described in $\boldsymbol{A}$ in A53T patient neurons at day 90 . Scale bars, $5 \mu \mathrm{m}$. For all quantifications, values are the mean \pm SEM. ${ }^{*} p<0.05$.

ically reduced, whereas the punctated pattern within neuronal extensions appeared to be restored by 758 (Fig. 6A). To confirm that 758 could reduce $\alpha$-syn pathology in the cell bodies and neurites in an additional patient line, A53T $\alpha$-syn-expressing midbrain neurons were treated with 758 and analyzed for Thio S fluorescence. We found similar effects in A53T neurons including a decline in the number of cells with $\alpha$-syn staining at the cell body and reduced neuritic pathology to a level that was similar to isogenic corrected control lines (Fig. 6B). These data indicate that GCase modulation by 758 can reduce amyloidogenic $\alpha$-syn in different types of synucleinopathies with distinct disease causing mutations.

Because previous studies indicated that $\alpha$-syn accumulation disrupted protein maturation and hydrolase activity in lysosomes 

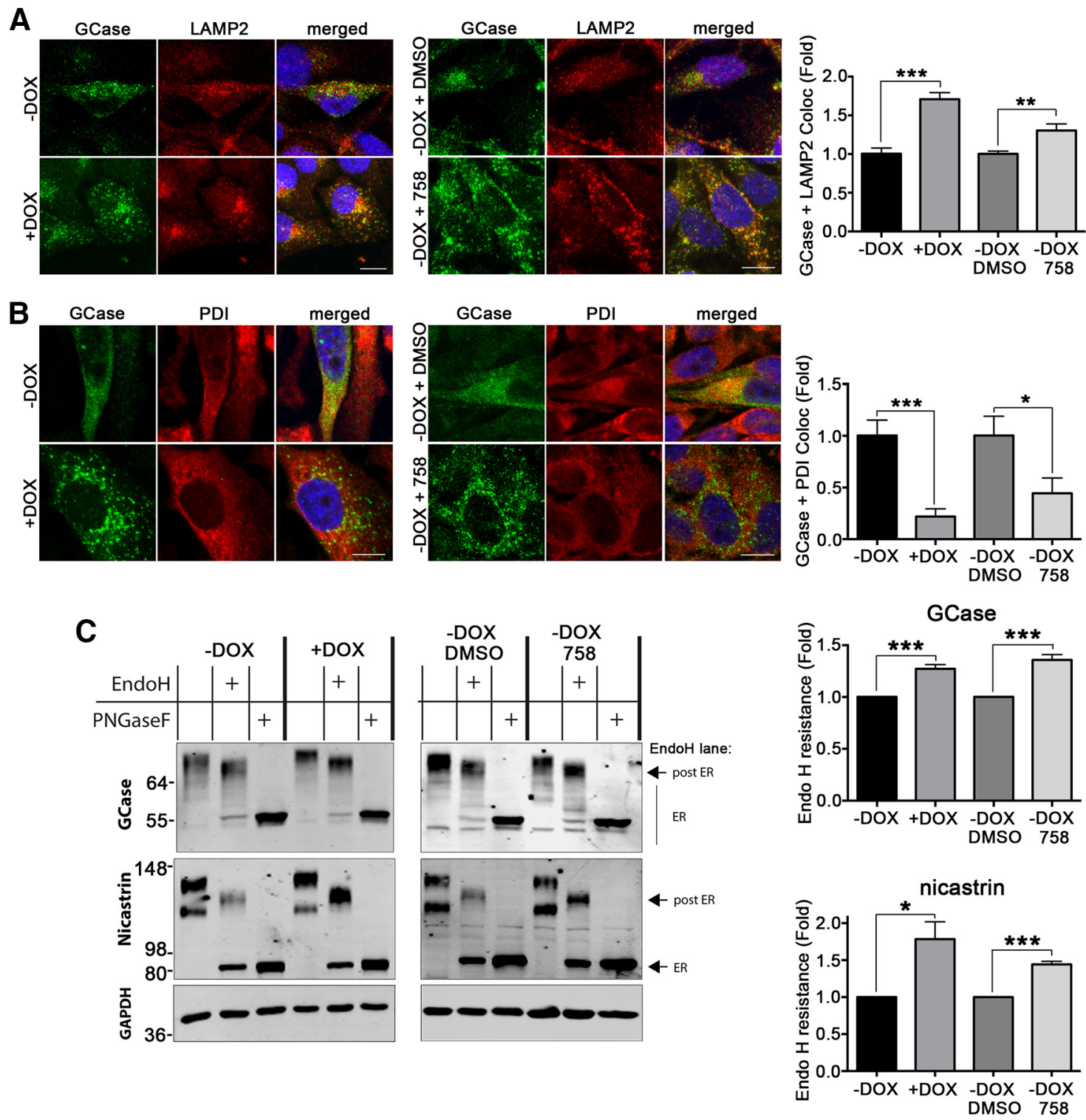

Figure 7. 758-mediated reduction of $\alpha$-syn reduces downstream cellular pathology associated with $\alpha$-syn accumulation. $\mathrm{H} 4$ neuroglioma cells were treated with $5 \mu \mathrm{m} 758$ for $5 \mathrm{~d}$ and analyzed for changes in protein maturation and trafficking. A, H4 cells were fixed and immunostained for GCase (8E4 antibody, green) and LAMP2 (red) to detect colocalization with lysosomes. Right, Quantification of colocalization $(n=6)$. B, ER accumulation of GCase by $\alpha$-syn documented by immunostaining for ER resident, PDI (red), is reversed by DOX or 758 treatment. Right, Quantification of colocalization $(n=6)$. Scale bars, $10 \mu \mathrm{m}$. Nuclei were detected with DAPI (blue). C, Analysis of protein maturation by Endo H treatment followed by Western blot for GCase (8E4) or nicastrin. GAPDH was used as a loading control. Molecular weight marker is indicated in kilodaltons. Right, Quantification of Endo H resistance of GCase or nicastrin. Values are the mean \pm SEM. ${ }^{* * *} p<0.001$, ${ }^{* *} p<0.01,{ }^{*} p<0.05$.

of patient neurons (Chung et al., 2013; Mazzulli et al., 2016), we tested whether 758 -mediated $\alpha$-syn reduction was sufficient to reverse this pathological phenotype. We found that $\alpha$-syn accumulation in $\mathrm{H} 4$ neuroglioma cells reduced the amount of GCase protein found in lysosomes by colocalization analysis with lysosomal marker LAMP2 (Fig. 7A), whereas it concomitantly increased the accumulation of GCase within ER compartments (Fig. $7 B$ ). This effect was partially reversed in parallel cultures treated with DOX to turn off $\alpha$-syn expression (Fig. 7 $A, B$ ). Importantly, 758-mediated clearance of $\alpha$-syn resulted in a significant elevation of GCase colocalized with LAMP2 and a decline of ER-localized GCase (Fig. $7 A, B$ ).

To further probe changes in the subcellular location and trafficking of GCase, analysis of carbohydrate modification of the protein was performed by glycosidase treatment of $\mathrm{H} 4$ lysates followed by Western blot. GCase is cotranslationally modified by the addition of $\mathrm{N}$-linked glycans that are progressively remodeled as the protein moves unidirectionally through the secretory pathway (Bergmann and Grabowski, 1989). Upon entry into the Golgi apparatus, surface exposed N-linked glycans of GCase are enzymatically converted to form complex-type oligosaccharides that resist cleavage by Endo $\mathrm{H}$. PNGase F digests all oligosaccharide types and is used to reveal the molecular weight of the unmodified polypeptide backbone. Digestion of $\mathrm{H} 4$ lysates with Endo $\mathrm{H}$ revealed reduced levels of post-ER GCase in $\alpha$-syn overexpressing cells (Fig. 7C; compare Endo $\mathrm{H}+$ lane of $-\mathrm{DOX}$ with + DOX). A 5 d incubation of $\alpha$-syn overexpressing cells with 758 elevated Endo H-resistant GCase to the same extent as control cells (Fig. 7C; compare Endo H+ lane of DMSO with 758).

To determine whether 758-mediated reduction of $\alpha$-syn could improve the maturation of a protein other than GCase, we measured the Endo $\mathrm{H}$ resistance of nicastrin. Nicastrin 
A
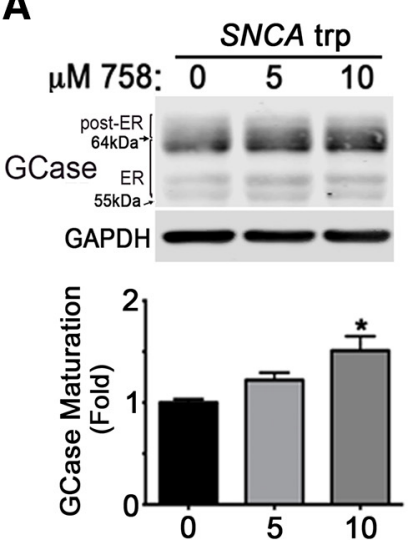

D

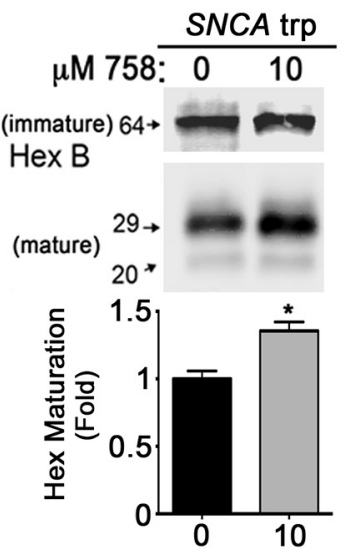

G

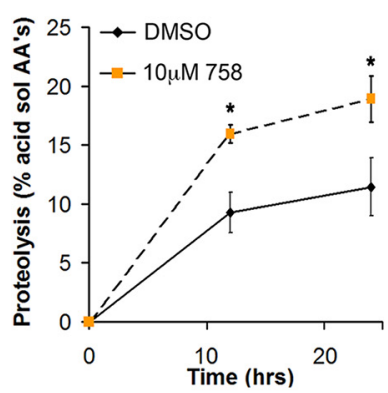

B
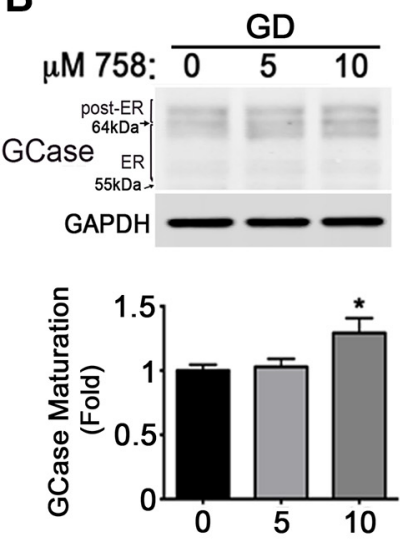

E

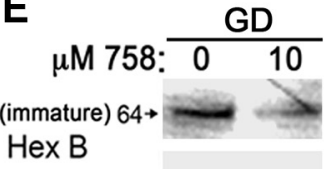
Hex B

(mature)

20

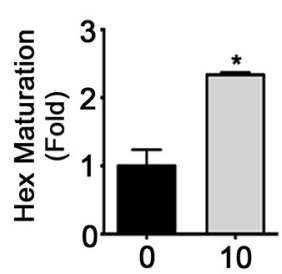

H

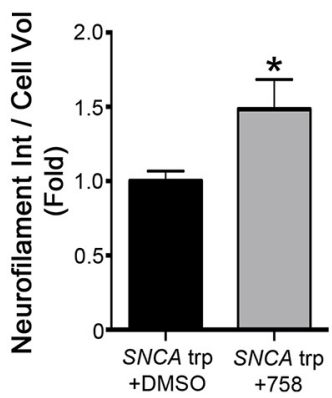

C
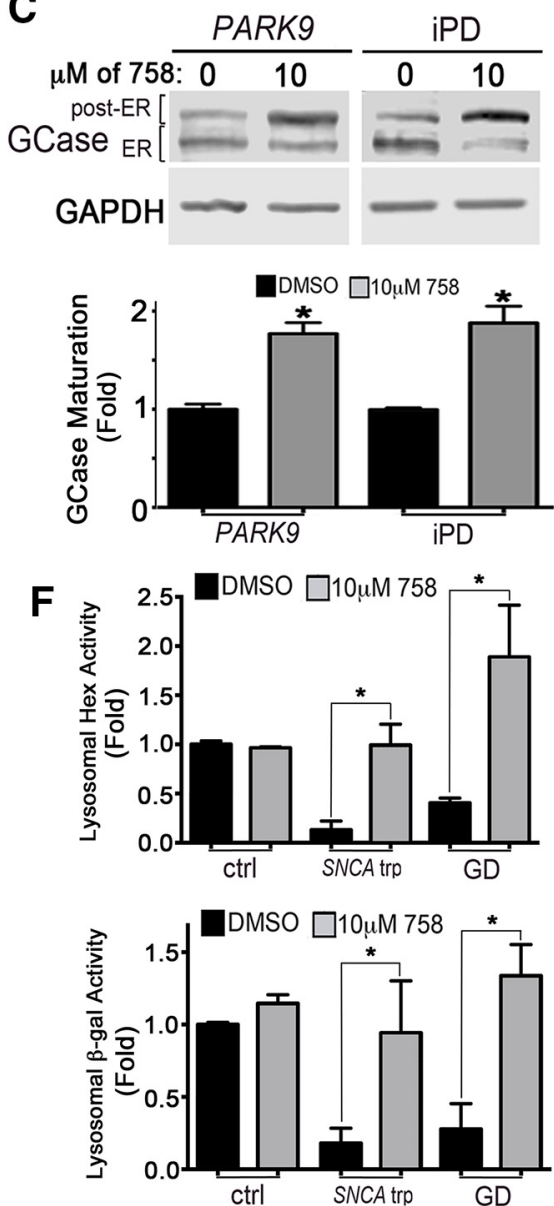

Figure 8. 758 improves protein maturation and lysosomal function in human synucleinopathy midbrain models. $A-C$, Analysis of GCase maturation by Western blot. SNCA trp, GD, PARK9 mutant or iPD neurons at day 120 were treated with 0,5 , and $10 \mu \mathrm{m} 758$ for $8 \mathrm{~d}$. GAPDH was used as a loading control. Quantification of post ER-ER ratio is shown below $\left(n=3,{ }^{*} p<0.05\right)$. $D, E$, Analysis of Hex B maturation by Western blot of SNCA trp or GD midbrain neurons treated with $10 \mu \mathrm{m} 758$ for $8 \mathrm{~d}$. Quantification of mature-immature ratio is shown below ( $n=3$, $\left.{ }^{*} p<0.05\right)$. Molecular weight marker is indicated in kilodaltons. $\boldsymbol{F}$, Measurement of live-cell lysosomal activity of hex and $\beta$-Gal in day 120 SNCA trp and GD neurons $\left(n=4,{ }^{*} p<0.05\right)$. $\boldsymbol{G}$, Measurement of proteolysis rate by quantification of acid-soluble amino acids (AA's) excreted in the media over time in living SNCA trp neurons treated with $10 \mu \mathrm{m} 758\left(n=4,{ }^{*} p<0.05\right)$. $\boldsymbol{H}$, Neurite quantification by neurofilament immunofluorescence intensity in SNCA trp neurons treated with $10 \mu \mathrm{m} 758$ for $14 \mathrm{~d}$, normalized to total cell volume $\left(n=9,{ }^{*} p<0.05\right)$. For all quantifications, values are the mean \pm SEM.

similarly acquires complex-type oligosaccharides as it matures through the secretory pathway, and its maturation is affected by $\alpha$-syn accumulation (Chung et al., 2013). Consistent with previous data (Chung et al., 2013), we found that $\alpha$-syn accumulation reduced the levels of Endo $\mathrm{H}$-resistant nicastrin (Fig. $7 C$; compare Endo $\mathrm{H}+$ lane of $-\mathrm{DOX}$ with $+\mathrm{DOX})$. Similar to the effect on GCase, 758 treatment in $\alpha$-syn cells elevated the levels of post-ER nicastrin (Fig. 7C; compare Endo $\mathrm{H}+$ lane of DMSO with 758). Together with the immunofluorescence analysis, our data indicates that $\alpha$-syn accumulation perturbs the subcellular location of proteins that move through the secretory pathway, likely through interfering with protein trafficking events. These data are consistent with previous work from our group and others (Cooper et al., 2006; Thayanidhi et al., 2010; Mazzulli et al., 2011, 2016; Chung et al., 2013; Credle et al., 2015). Importantly, it appears that 758 -mediated reduction of $\alpha$-syn is sufficient to at least partially reverse this downstream pathogenic phenotype.

To confirm our results in patient midbrain neurons, we treated cultures with 758 for $8 \mathrm{~d}$ and hydrolase maturation of GCase and lysosomal Hex B was assessed by Western blot. We found that 758 elevated the levels of mature hydrolase forms in all 
patient lines examined, indicated by enhancement of mature/ immature ratios (Fig. 8A-E). 758 restored the activity of Hex within lysosomal compartments to control levels, indicating that the mature protein documented by Western blot was active (Fig. $8 F)$. Since we previously found that $\beta$-galactosidase $(\beta$-Gal) activity was reduced in patient neurons, we measured the effect of 758 on its lysosomal activity and found a significant improvement (Fig. 8F, bottom). Importantly, 758 did not affect the activity of hex and $\beta$-Gal in control neurons, consistent with the notion that the primary action of 758 is to improve GCase activity, which subsequently reduces $\alpha$-syn and reverses its downstream effects on the lysosomal system (Fig. $8 F$ ). As a separate assessment of lysosomal function, we measured the degradation rate of long-lived proteins in SNCA trp and found that 758 significantly elevated proteolysis (Fig. $8 G$ ). Finally, assessment of neuron viability measured by neurofilament immunostaining indicated a significant improvement by 758 in day 120 SNCA trp neurons (Fig. $8 H$ ). Together, these results show that activation of GCase by non-inhibitory small molecules can reverse pathological effects of $\alpha$-syn in midbrain neuronal cultures, and suggest that activation of GCase may provide therapeutic benefit for synucleinopathy patients.

\section{Discussion}

The development of therapies for neurodegenerative disorders has proven challenging, in part due to lack of validated targets and accurate human models that faithfully recapitulate agerelated disease processes. Previously, we showed that midbrain neurons derived from SNCA trp, GD, or iPD neurons generated in vitro shared many well established neuropathological features observed in synucleinopathy patients. These included the presence of amyloidogenic $\alpha$-syn within cell bodies and neurites, the accumulation of insoluble $\alpha$-syn, and reduced neuronal viability (Mazzulli et al., 2016). We also found that SNCA trp midbrain neurons that express WT GBA1 had reduced lysosomal activity of GCase that was reversible by shRNA-mediated knock-down of $\alpha$-syn (Mazzulli et al., 2016). This suggested that reduced GCase activity might play a pathogenic role in synucleinopathy patients that harbor either WT or mutant GBA1. Consistent with this notion, WT GCase activity is decreased in blood samples and postmortem brains of sporadic PD patients (Gegg et al., 2012; Alcalay et al., 2015; Rocha et al., 2015a).

Previous cell culture studies showed that GCase knock-down or expression of loss-of-function mutant GBA1 results in $\alpha$-syn accumulation (Cullen et al., 2011; Mazzulli et al., 2011, 2016; Xu et al., 2011; Schöndorf et al., 2014; Bae et al., 2015; Sun et al., 2015). Using cell-free in vitro models, we showed previously that purified GluCer directly influenced the aggregation of recombinant $\alpha$-syn, through promoting the formation of soluble oligomers and amyloidogenic $\alpha$-syn at lysosomal pH 5.0 (Mazzulli et al., 2011). In addition, several other groups have shown that $\alpha$-syn aggregation can be induced by reduction of GCase activity in cells or animal models, suggesting a close link between $\alpha$-syn metabolism and GCase activity (Manning-Boğ et al., 2009; Xu et al., 2011; Osellame et al., 2013; Schöndorf et al., 2014; Rocha et al., 2015c). Perhaps the most compelling evidence that GCase deficiency contributes to pathophysiology of synucleinopathies is derived from clinical and genetic evidence that links loss-offunction mutations in GBA1 to both PD and dementia with Lewy bodies (Siebert et al., 2014).

Consistent with the soundly documented link between GCase loss-of-function and $\alpha$-syn accumulation, recent studies have shown that improvement of GCase activity through virus- mediated overexpression in synucleinopathy mouse models can reduce $\alpha$-syn and improve cognitive behaviors (Sardi et al., 2011, 2013; Rocha et al., 2015b). Here, we used several different human synucleinopathy models to determine whether small moleculemediated GCase activation could reduce $\alpha$-syn and reverse downstream cellular pathology. Using a previously characterized modulator of GCase (758), we found that activation of the enzyme reduced lysosomal GluCer accumulation and lowered $\alpha$-syn levels in these models. Based on previous studies, we hypothesize that the reduction of GluCer makes $\alpha$-syn more amenable to degradation, through destabilization of $\alpha$-syn and subsequent clearance through the lysosomal system (Cuervo et al., 2004; Mazzulli et al., 2011). However, further studies are required to determine the mechanistic relationship between GCase activity, substrate levels, and the clearance of $\alpha$-syn.

Importantly, we demonstrate that 758 affected several patient lines with distinct PD-causing mutations. Although the factors that initiate $\alpha$-syn aggregation in these patient lines are different, we found that 758 improved GCase activity and reduced $\alpha$-syn levels in all lines tested. In addition to patient lines, we found that 758 could reduce $\alpha$-syn in neuronal cultures from healthy controls (Fig. 6A), consistent with activation of both WT and mutant GCase by 758 (Fig. 2C). This indicates that $\alpha$-syn levels can be reduced in neuronal lines with and without PD-linked mutations, and further implicate this therapeutic strategy may be extended to a wide range of synucleinopathies that include both carriers and non-carriers of GBA1 mutations.

The data presented here indicate that 758-mediated reduction of $\alpha$-syn can also reverse associated downstream pathogenic phenotypes, such as disrupted hydrolase maturation and lysosomal enzyme activity (Figs. 7, 8). We have previously shown that perturbations in hydrolase maturation and reduced lysosomal activity in PD patient neurons leads to augmented $\alpha$-syn accumulation, whereas $\alpha$-syn knock-down improved enzyme maturation and activity, indicating an $\alpha$-syn-specific effect (Mazzulli et al., 2016). In support of this notion, the data here shows that direct activation of GCase leads to a decrease in $\alpha$-syn, which in turn reduces downstream pathological effects on protein maturation and the lysosomal system (Figs. 7, 8).

Therapeutically targeting lysosomal enzymes, such as GCase, allows for measurement of the enzyme activation and substrate reduction, both of which could be measured noninvasively in fluids including blood and CSF (Parnetti et al., 2014). Such a direct measure is an advantage in patient populations that normally rely on measurements of amyloidogenic proteins or clinical outcomes as readouts of therapeutic efficacy. Although further improvement and testing of 758 will be required before clinical use, it nonetheless provides an important starting point for the development of mechanism-based targeted therapies for synucleinopathies.

\section{References}

Aflaki E, Stubblefield BK, Maniwang E, Lopez G, Moaven N, Goldin E, Marugan J, Patnaik S, Dutra A, Southall N, Zheng W, Tayebi N, Sidransky E (2014) Macrophage models of Gaucher disease for evaluating disease pathogenesis and candidate drugs. Sci Transl Med 6:240ra73. CrossRef Medline

Alcalay RN, Levy OA, Waters CC, Fahn S, Ford B, Kuo SH, Mazzoni P, Pauciulo MW, Nichols WC, Gan-Or Z, Rouleau GA, Chung WK, Wolf P, Oliva P, Keutzer J, Marder K, Zhang X (2015) Glucocerebrosidase activity in Parkinson's disease with and without GBA mutations. Brain 138: 2648-2658. CrossRef Medline

Baba M, Nakajo S, Tu PH, Tomita T, Nakaya K, Lee VM, Trojanowski JQ, 
Iwatsubo T (1998) Aggregation of alpha-synuclein in Lewy bodies of sporadic Parkinson's disease and dementia with Lewy bodies. Am J Pathol 152:879-884. Medline

Bae EJ, Yang NY, Lee C, Lee HJ, Kim S, Sardi SP, Lee SJ (2015) Loss of glucocerebrosidase 1 activity causes lysosomal dysfunction and alphasynuclein aggregation. Exp Mol Med 47:e153. CrossRef Medline

Bergmann JE, Grabowski GA (1989) Posttranslational processing of human lysosomal acid beta-glucosidase: a continuum of defects in Gaucher disease type 1 and type 2 fibroblasts. Am J Hum Genet 44:741-750. Medline

Bolhuis PA, Oonk JG, Kamp PE, Ris AJ, Michalski JC, Overdijk B, Reuser AJ (1987) Ganglioside storage, hexosaminidase lability, and urinary oligosaccharides in adult Sandhoffs disease. Neurology 37:75-81. CrossRef Medline

Brady RO, Kanfer J, Shapiro D (1965) The metabolism of glucocerebrosides: I. Purification and properties of a glucocerebroside-cleaving enzyme from spleen tissue. J Biol Chem 240:39-43. Medline

Chung CY, Khurana V, Auluck PK, Tardiff DF, Mazzulli JR, Soldner F, Baru V, Lou Y, Freyzon Y, Cho S, Mungenast AE, Muffat J, Mitalipova M, Pluth MD, Jui NT, Schüle B, Lippard SJ, Tsai LH, Krainc D, Buchwald SL, et al. (2013) Identification and rescue of alpha-synuclein toxicity in Parkinson patient-derived neurons. Science 342:983-987. CrossRef Medline

Cleeter MW, Chau KY, Gluck C, Mehta A, Hughes DA, Duchen M, Wood NW, Hardy J, Mark Cooper J, Schapira AH (2013) Glucocerebrosidase inhibition causes mitochondrial dysfunction and free radical damage. Neurochem Int 62:1-7. CrossRef Medline

Cooper AA, Gitler AD, Cashikar A, Haynes CM, Hill KJ, Bhullar B, Liu K, Xu K, Strathearn KE, Liu F, Cao S, Caldwell KA, Caldwell GA, Marsischky G, Kolodner RD, Labaer J, Rochet JC, Bonini NM, Lindquist S (2006) Alpha-synuclein blocks ER-Golgi traffic and Rab1 rescues neuron loss in Parkinson's models. Science 313:324-328. CrossRef Medline

Credle JJ, Forcelli PA, Delannoy M, Oaks AW, Permaul E, Berry DL, Duka V, Wills J, Sidhu A (2015) $\alpha$-Synuclein-mediated inhibition of ATF6 processing into COPII vesicles disrupts UPR signaling in Parkinson's disease. Neurobiol Dis 76:112-125. CrossRef Medline

Cuervo AM, Stefanis L, Fredenburg R, Lansbury PT, Sulzer D (2004) Impaired degradation of mutant alpha-synuclein by chaperone-mediated autophagy. Science 305:1292-1295. CrossRef Medline

Cullen V, Sardi SP, Ng J, Xu YH, Sun Y, Tomlinson JJ, Kolodziej P, Kahn I, Saftig P, Woulfe J, Rochet JC, Glicksman MA, Cheng SH, Grabowski GA, Shihabuddin LS, Schlossmacher MG (2011) Acid beta-glucosidase mutants linked to Gaucher disease, Parkinson disease, and Lewy body dementia alter alpha-synuclein processing. Ann Neurol 69:940-953. CrossRef Medline

Duda JE, Giasson BI, Mabon ME, Lee VM, Trojanowski JQ (2002) Novel antibodies to synuclein show abundant striatal pathology in Lewy body diseases. Ann Neurol 52:205-210.

Gegg ME, Burke D, Heales SJ, Cooper JM, Hardy J, Wood NW, Schapira AH (2012) Glucocerebrosidase deficiency in substantia nigra of parkinson disease brains. Ann Neurol 72:455-463. CrossRef Medline

Gitler AD, Chesi A, Geddie ML, Strathearn KE, Hamamichi S, Hill KJ, Caldwell KA, Caldwell GA, Cooper AA, Rochet JC, Lindquist S (2009) Alpha-synuclein is part of a diverse and highly conserved interaction network that includes PARK9 and manganese toxicity. Nat Genet 41: 308-315. CrossRef Medline

Halliday GM, Holton JL, Revesz T, Dickson DW (2011) Neuropathology underlying clinical variability in patients with synucleinopathies. Acta Neuropathologica 122:187-204. CrossRef Medline

Kriks S, Shim JW, Piao J, Ganat YM, Wakeman DR, Xie Z, Carrillo-Reid L, Auyeung G, Antonacci C, Buch A, Yang L, Beal MF, Surmeier DJ, Kordower JH, Tabar V, Studer L (2011) Dopamine neurons derived from human ES cells efficiently engraft in animal models of Parkinson's disease. Nature 480:547-551. CrossRef Medline

Lee BR, Kamitani T (2011) Improved immunodetection of endogenous alpha-synuclein. PloS One 6:e23939. CrossRef Medline

Manning-Boğ AB, Schüle B, Langston JW (2009) Alpha-synuclein-glucocerebrosidase interactions in pharmacological Gaucher models: a biological link between Gaucher disease and parkinsonism. Neurotoxicology 30:1127-1132. CrossRef Medline

Mazzulli JR, Mishizen AJ, Giasson BI, Lynch DR, Thomas SA, Nakashima A, Nagatsu T, Ota A, Ischiropoulos H (2006) Cytosolic catechols inhibit alpha-synuclein aggregation and facilitate the formation of intracellular soluble oligomeric intermediates. J Neurosci 26:10068-10078. CrossRef Medline
Mazzulli JR, Xu YH, Sun Y, Knight AL, McLean PJ, Caldwell GA, Sidransky E, Grabowski GA, Krainc D (2011) Gaucher disease glucocerebrosidase and alpha-synuclein form a bidirectional pathogenic loop in synucleinopathies. Cell 146:37-52. CrossRef Medline

Mazzulli JR, Zunke F, Isacson O, Studer L, Krainc D (2016) $\alpha$-Synucleininduced lysosomal dysfunction occurs through disruptions in protein trafficking in human midbrain synucleinopathy models. Proc Natl Acad Sci U S A 113:1931-1936. CrossRef Medline

McCann H, Stevens CH, Cartwright H, Halliday GM (2014) $\alpha$-Synucleinopathy phenotypes. Parkinsonism and related disorders 20:S62S67. CrossRef Medline

Migdalska-Richards A, Schapira AH (2016) The relationship between glucocerebrosidase mutations and Parkinson disease. J Neurochem. Advance online publication. doi: 10.1111/jnc.13385. Retrieved February 10, 2016. Medline

Osellame LD, Rahim AA, Hargreaves IP, Gegg ME, Richard-Londt A, Brandner S, Waddington SN, Schapira AH, Duchen MR (2013) Mitochondria and quality control defects in a mouse model of Gaucher disease: links to Parkinson's disease. Cell Metab 17:941-953. CrossRef Medline

Park JS, Mehta P, Cooper AA, Veivers D, Heimbach A, Stiller B, Kubisch C, Fung VS, Krainc D, Mackay-Sim A, Sue CM (2011) Pathogenic effects of novel mutations in the P-type ATPase ATP13A2 (PARK9) causing KuforRakeb syndrome, a form of early-onset parkinsonism. Hum Mutat 32: 956-964. CrossRef Medline

Parnetti L, Chiasserini D, Persichetti E, Eusebi P, Varghese S, Qureshi MM, Dardis A, Deganuto M, De Carlo C, Castrioto A, Balducci C, Paciotti S, Tambasco N, Bembi B, Bonanni L, Onofrj M, Rossi A, Beccari T, El-Agnaf O, Calabresi P (2014) Cerebrospinal fluid lysosomal enzymes and alpha-synuclein in Parkinson's disease. Mov Disord 29:1019-1027. CrossRef Medline

Patnaik S, Zheng W, Choi JH, Motabar O, Southall N, Westbroek W, Lea WA, Velayati A, Goldin E, Sidransky E, Leister W, Marugan JJ (2012) Discovery, structure-activity relationship, and biological evaluation of noninhibitory small molecule chaperones of glucocerebrosidase. J Med Chem 55:5734-5748. CrossRef Medline

Rocha EM, Smith GA, Park E, Cao H, Brown E, Hallett P, Isacson O (2015a) Progressive decline of glucocerebrosidase in aging and Parkinson's disease. Ann Clin Transl Neurol 2:433-438. CrossRef Medline

Rocha EM, Smith GA, Park E, Cao H, Brown E, Hayes MA, Beagan J, McLean JR, Izen SC, Perez-Torres E, Hallett PJ, Isacson O (2015b) Glucocerebrosidase gene therapy prevents alpha-synucleinopathy of midbrain dopamine neurons. Neurobiol Dis 82:495-503. CrossRef Medline

Rocha EM, Smith GA, Park E, Cao H, Graham AR, Brown E, McLean JR, Hayes MA, Beagan J, Izen SC, Perez-Torres E, Hallett PJ, Isacson O (2015c) Sustained systemic glucocerebrosidase inhibition induces brain alpha-synuclein aggregation, microglia and complement C1q activation in mice. Antioxid Redox Signal 23:550-564. CrossRef Medline

Ryan SD, Dolatabadi N, Chan SF, Zhang X, Akhtar MW, Parker J, Soldner F, Sunico CR, Nagar S, Talantova M, Lee B, Lopez K, Nutter A, Shan B, Molokanova E, Zhang Y, Han X, Nakamura T, Masliah E, Yates JR 3rd, et al. (2013) Isogenic human iPSC Parkinson's model shows nitrosative stress-induced dysfunction in MEF2-PGC1alpha transcription. Cell 155: 1351-1364. CrossRef Medline

Sardi SP, Clarke J, Kinnecom C, Tamsett TJ, Li L, Stanek LM, Passini MA, Grabowski GA, Schlossmacher MG, Sidman RL, Cheng SH, Shihabuddin LS (2011) CNS expression of glucocerebrosidase corrects $\alpha$-synuclein pathology and memory in a mouse model of Gaucher-related synucleinopathy. Proc Natl Acad Sci U S A 108:12101-12106. CrossRef Medline

Sardi SP, Clarke J, Viel C, Chan M, Tamsett TJ, Treleaven CM, Bu J, Sweet L, Passini MA, Dodge JC, Yu WH, Sidman RL, Cheng SH, Shihabuddin LS (2013) Augmenting CNS glucocerebrosidase activity as a therapeutic strategy for parkinsonism and other Gaucher-related synucleinopathies. Proc Natl Acad Sci U S A 110:3537-3542. CrossRef Medline

Schöndorf DC, Aureli M, McAllister FE, Hindley CJ, Mayer F, Schmid B, Sardi SP, Valsecchi M, Hoffmann S, Schwarz LK, Hedrich U, Berg D, Shihabuddin LS, Hu J, Pruszak J, Gygi SP, Sonnino S, Gasser T, Deleidi M (2014) iPSC-derived neurons from GBA1-associated Parkinson's disease patients show autophagic defects and impaired calcium homeostasis. Nat Commun 5:4028. CrossRef Medline

Schultheis PJ, Fleming SM, Clippinger AK, Lewis J, Tsunemi T, Giasson B, Dickson DW, Mazzulli JR, Bardgett ME, Haik KL, Ekhator O, Chava AK, Howard J, Gannon M, Hoffman E, Chen Y, Prasad V, Linn SC, 
Tamargo RJ, Westbroek W, et al. (2013) Atp13a2-deficient mice exhibit neuronal ceroid lipofuscinosis, limited alpha-synuclein accumulation and age-dependent sensorimotor deficits. Hum Mol Genet 22: 2067-2082. CrossRef Medline

Sidransky E, Nalls MA, Aasly JO, Aharon-Peretz J, Annesi G, Barbosa ER, Bar-Shira A, Berg D, Bras J, Brice A, Chen CM, Clark LN, Condroyer C, De Marco EV, Dürr A, Eblan MJ, Fahn S, Farrer MJ, Fung HC, Gan-Or Z, et al. (2009) Multicenter analysis of glucocerebrosidase mutations in Parkinson's disease. N Engl J Med 361:1651-1661. CrossRef Medline

Siebert M, Sidransky E, Westbroek W (2014) Glucocerebrosidase is shaking up the synucleinopathies. Brain 137:1304-1322. CrossRef Medline

Soldner F, Laganière J, Cheng AW, Hockemeyer D, Gao Q, Alagappan R, Khurana V, Golbe LI, Myers RH, Lindquist S, Zhang L, Guschin D, Fong LK, Vu BJ, Meng X, Urnov FD, Rebar EJ, Gregory PD, Zhang HS, Jaenisch $\mathrm{R}$ (2011) Generation of isogenic pluripotent stem cells differing exclusively at two early onset Parkinson point mutations. Cell 146:318-331. CrossRef Medline

Spillantini MG, Schmidt ML, Lee VM, Trojanowski JQ, Jakes R, Goedert M (1997) Alpha-synuclein in Lewy bodies. Nature 388:839-840. CrossRef Medline

Sun Y, Florer J, Mayhew CN, Jia Z, Zhao Z, Xu K, Ran H, Liou B, Zhang W, Setchell KD, Gu J, Grabowski GA (2015) Properties of neurons derived from induced pluripotent stem cells of Gaucher disease type 2 patient fibroblasts: potential role in neuropathology. PloS One 10:e0118771. CrossRef Medline

Thayanidhi N, Helm JR, Nycz DC, Bentley M, Liang Y, Hay JC (2010) $\alpha$-Synuclein delays endoplasmic reticulum (ER)-to-Golgi transport in mammalian cells by antagonizing ER/Golgi SNAREs. Mol Biol Cell 21: 1850-1863. CrossRef Medline

Tsunemi T, Krainc D (2014) $\mathrm{Zn}^{2+}$ dyshomeostasis caused by loss of ATP13A2/PARK9 leads to lysosomal dysfunction and alpha-synuclein accumulation. Hum Mol Genet 23:2791-2801. CrossRef Medline

van der Brug MP, Singleton A, Gasser T, Lewis PA (2015) Parkinson's disease: from human genetics to clinical trials. Sci Transl Med 7:205ps20. CrossRef Medline

van Weely S, Brandsma M, Strijland A, Tager JM, Aerts JM (1993) Demonstration of the existence of a second, non-lysosomal glucocerebrosidase that is not deficient in Gaucher disease. Biochim Biophys Acta 1181: 55-62. CrossRef Medline

Xu YH, Sun Y, Ran H, Quinn B, Witte D, Grabowski GA (2011) Accumulation and distribution of alpha-synuclein and ubiquitin in the CNS of Gaucher disease mouse models. Mol Genet Metab 102:436-447. CrossRef Medline

Yap TL, Velayati A, Sidransky E, Lee JC (2013) Membrane-bound alphasynuclein interacts with glucocerebrosidase and inhibits enzyme activity. Mol Genet Metab 108:56-64. CrossRef Medline 